\title{
Functional Amyloids
}

\author{
Daniel Otzen ${ }^{1}$ and Roland Riek ${ }^{2}$ \\ ${ }^{1}$ iNANO, Aarhus University, DK-8000 Aarhus C, Denmark \\ ${ }^{2}$ Laboratory of Physical Chemistry, Swiss Federal Institute of Technology, CH-8093 Zürich, Switzerland \\ Correspondence: roland.riek@phys.chem.ethz.ch; dao@inano.au.dk
}

When protein/peptides aggregate, they usually form the amyloid state consisting of cross $\beta$-sheet structure built by repetitively stacked $\beta$-strands forming long fibrils. Amyloids are usually associated with disease including Alzheimer's. However, amyloid has many useful features. It efficiently transforms protein from the soluble to the insoluble state in an essentially two-state process, while its repetitive structure provides high stability and a robust prion-like replication mechanism. Accordingly, amyloid is used by nature in multifaceted and ingenious ways of life, ranging from bacteria and fungi to mammals. These include (1) Structure: Templating for small chemical molecules (Pmel17), biofilm formation in bacteria (curli), assisting aerial hyphae formation in streptomycetes (chaplins) or monolayer formation at a surface (hydrophobins). (2) Reservoirs: A storage state for peptide/proteins to protect them from their surroundings or vice versa (storage of peptide hormones in mammalian secretory granules or major basic protein in eosinophils). (3) Information carriers: The fungal immune system (HET-s prion in Podospora anserina, yeast prions) or long-term memory (e.g., mnemons in yeast, cytoplasmic polyadenylation element-binding protein in aplysia). Aggregation is also used to (4) "suppress" the function of the soluble protein (e.g., Cdc19 in yeast stress granules), or (5) "signaling" through formation of oligomers (e.g., HET-s prion, necroptosis-related proteins RIP1/RIP3). This review summarizes current knowledge on functional amyloids with a focus on the amyloid systems curli in bacteria, HET-s prion in $P$. anserina, and peptide hormone storage in mammals together with an attempt to highlight differences between functional and disease-associated amyloids.

\begin{abstract}
A myloids are associated with more than 20 Ahuman diseases including Alzheimer's, Parkinson's, prion diseases, and type II diabetes (Chiti and Dobson 2006; Greenwald and Riek 2010; Riek and Eisenberg 2016). In these socalled amyloid-associated or deposition diseases, insoluble amyloid aggregates deposit extraor intracellularly in tissues and organs. In all cases, aggregation is attributed to misfolding of a specific protein. These aggregates are com-
\end{abstract}

posed of the so-called cross- $\beta$-sheet motif, first described by Astbury in 1935 based on X-ray fiber diffraction measurements of poached egg white (Astbury et al. 1935). Thus, all these diseases are linked by the amyloid state, a state that can also be induced by heat-induced misfolding of a protein completely unconnected to disease (hen egg white lysozyme). Accordingly, it came as a great surprise that amyloid could also have positive, that is, functional, roles in life (Chap-

Editors: Richard I. Morimoto, F. Ulrich Hartl, and Jeffery W. Kelly

Additional Perspectives on Protein Homeostasis available at www.cshperspectives.org

Copyright (C) 2019 Cold Spring Harbor Laboratory Press; all rights reserved; doi: 10.1101/cshperspect.a033860

Cite this article as Cold Spring Harb Perspect Biol 2019;11:a033860 
man et al. 2002; Maddelein et al. 2002; Gebbink et al. 2005; Fowler et al. 2006; Maji et al. 2009a). But, perhaps we should not be so surprised. In the universe of protein folds, the amyloid fold has unique and attractive properties so why should nature not exploit this? Given that these properties emerge from the amyloid structure, it is the aim of this review to summarize the scientific knowledge on functional amyloids from the viewpoint of structural biology. The large and growing list of known functional amyloids forces us to restrict ourselves to a small number of examples for the sake of overview and clarity. In addition, we will attempt to compare functional and disease-associated amyloids from 3D structures to proteostasis.

\section{THE STRUCTURE-ACTIVITY RELATIONSHIP OF AMYLOIDS}

Because the amyloid state is central to our review, we will briefly summarize its structure. We refer to Eisenberg and Sawaya (2017) for a detailed description. Amyloids are composed of many (usually hundreds to thousands) copies of a peptide/protein. These are arranged in a one-dimensional ordered and repetitive fashion to form (usually) unbranched fibrils, 6-12 nm in width (Sunde and Blake 1997) and up to several $\mu \mathrm{m}$ in length. The repeating substructure, termed the cross- $\beta$-sheet motif, consists of two layers of intermolecular $\beta$-sheets that run along the fiber axis (Fig. 1) (Astbury et al. 1935). Atomic resolution X-ray structures of microcrystals formed by short peptide segments of amyloid-forming proteins have been determined (Nelson et al. 2005; Sawaya et al. 2007). Viewed down the axis of the protofilament, the two $\beta$-sheets are seen to adhere by interdigitation of the side chains of the mating strands, much like the teeth of a zipper (Fig. 1). For this reason, this dualsheet motif is termed a steric zipper. The steric zipper interface is usually highly compact and usually excludes water. The interface can be arranged in eight different ways, giving rise to eight different classes of packings, some of which are shown in Figure 1. Although the $\beta$-sheets are of either a parallel or antiparallel nature, they are generally in-register. This means that in a parallel $\beta$-sheet, each $\beta$-strand lies exactly above the $\beta$-strand below it, and in an antiparallel sheet, each $\beta$-strand lies exactly above the $\beta$-strand two rows below it. Recent structures of amyloid composed of full-length proteins reveal a much greater structural complexity, involving a combination of multiple cross- $\beta$-sheet motifs (Wasmer et al. 2008; Colvin et al. 2016; Riek and Eisenberg 2016; Wälti et al. 2016; Fitzpatrick et al. 2017).

There are unique properties associated with the amyloid structure (Greenwald and Riek 2010). Amyloid is formed in a virtually two-state transition from the soluble (monomeric) to the insoluble (amyloid) state; the intermolecular nature of the cross- $\beta$-sheet motifs underlies a concentration-dependent folding that enables signaling and may form the basis for information storage. Its repetitiveness provides a structural template for replication, that is, $1 \mathrm{D}$-crystallike growth or a prion mechanism for transmission through the spread of small fibril fragments (Alper et al. 1967; Prusiner 1998). Within the cross- $\beta$-structure, close spacing of identical side chains can generate novel binding specificity absent in the monomeric state. For example, a single amphipathic $\beta$-strand would have only little affinity for a membrane, but an amyloid fibril made up of this peptide could bind tightly to lipids. Along with this cooperativity or avidity effect, the amyloid surface constitutes the repetitive display of a binding pocket increasing the overall apparent binding of a ligand, because it may just hop from one binding pocket to the next, leading to a very low overall dissociation rate. Indeed, functional amyloid in bacterial biofilm has been proposed to function as sponges or reservoirs, retaining small quorum-sensing molecules within the biofilm by providing such an extensive and repetitive (albeit low-specificity) binding surface (Seviour et al. 2015). In addition, amyloid segments may be used as oligomerization domains within a larger protein. The amyloid may thereby silence the protein/ peptide function (Soragni et al. 2015) or/and store the protein at high density inertly because of the high stability of the amyloid both under harsh chemical conditions as well as under biological proteolysis (Maji et al. 2009a; Saad et al. 2017). 

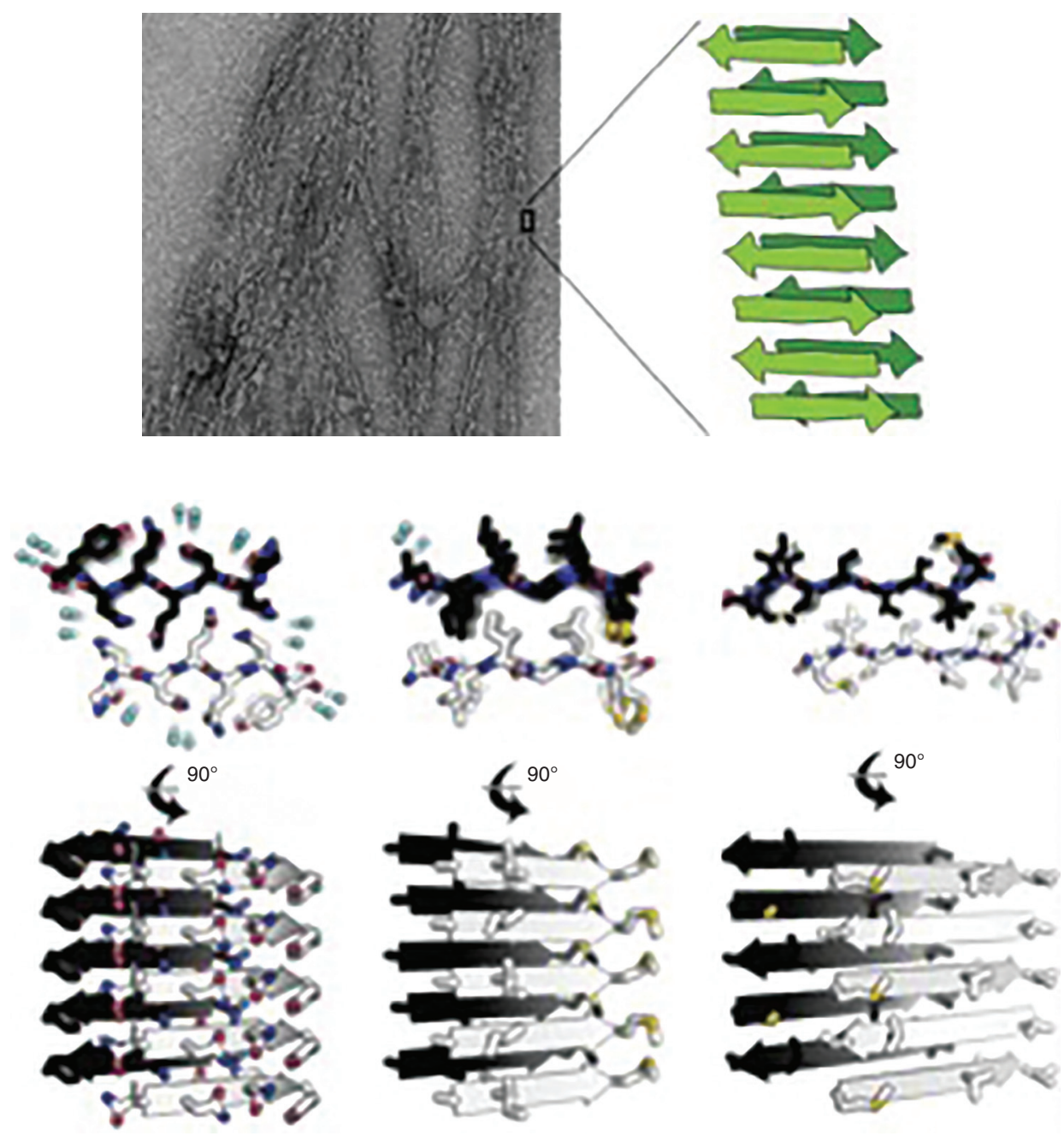

Figure 1. The 3D structures of amyloids. An electron micrograph of a peptide amyloid (top left). The zoom box (top right) depicts a cartoon version of the cross- $\beta$-sheet motif, with arrows indicating $\beta$-strands of individual peptides stabilized by both intermolecular hydrogen bonds and intermolecular side-chain interactions. Three 3D structures of peptide amyloids are shown below, illustrating three of the eight possible symmetry classes of steric zippers, with views both down the protofilament axis (middle row) and perpendicular to the axis (bottom row). One sheet is black and the other gray. Note that the water molecules (aqua spheres) are excluded from the tight interface between the sheets that form a dry zipper. Nitrogen atoms are colored blue, oxygen atoms red, and sulfur atoms yellow. $\beta$-Strands are shown as arrows. The structure on the left is composed of the peptide sequence QNNQQNY (protein data bank [PDB code]: 1YJP), the middle one of AIIGLM (2Y3J), and the right one of MVGGVVIA (2Y3K). (Figure created from data in Greenwald et al. 2018 and Riek and Eisenberg 2016.)

\section{AN OVERVIEW OF FUNCTIONAL AMYLOIDS}

As summarized in Table 1, there is a growing list of amyloids with functional properties. Functional amyloids can be grouped into (I) chemical storage, (II) structure, (III) information, (IV) loss-of-function, and (V) signaling/gain-offunction. Obviously, functional amyloids may belong to more than one group, because the amyloid structure by itself can have more than one function. Within group I-storage-we find numerous different peptide hormones, which are 
D. Otzen and R. Riek

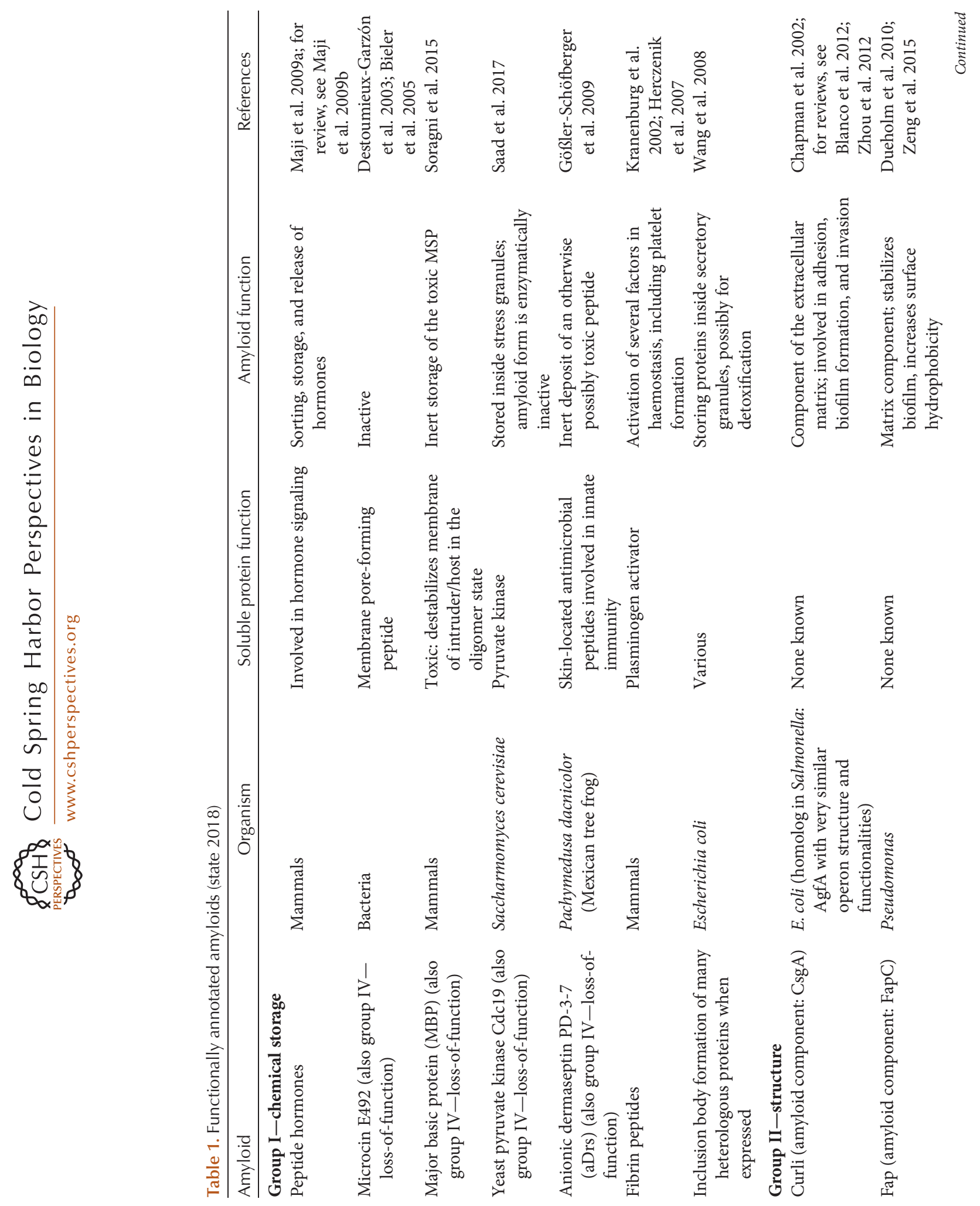


Functional Amyloids

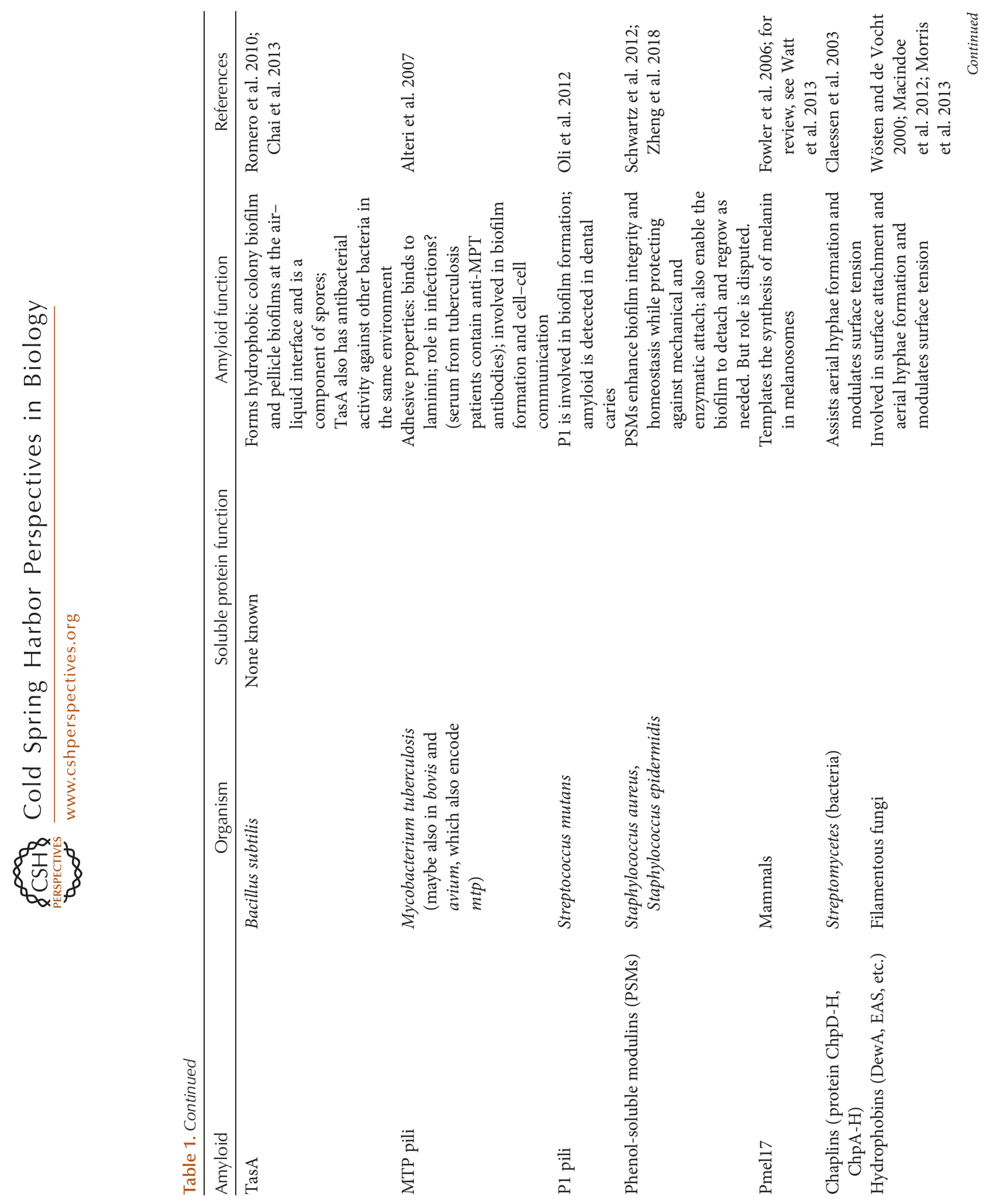


D. Otzen and R. Riek
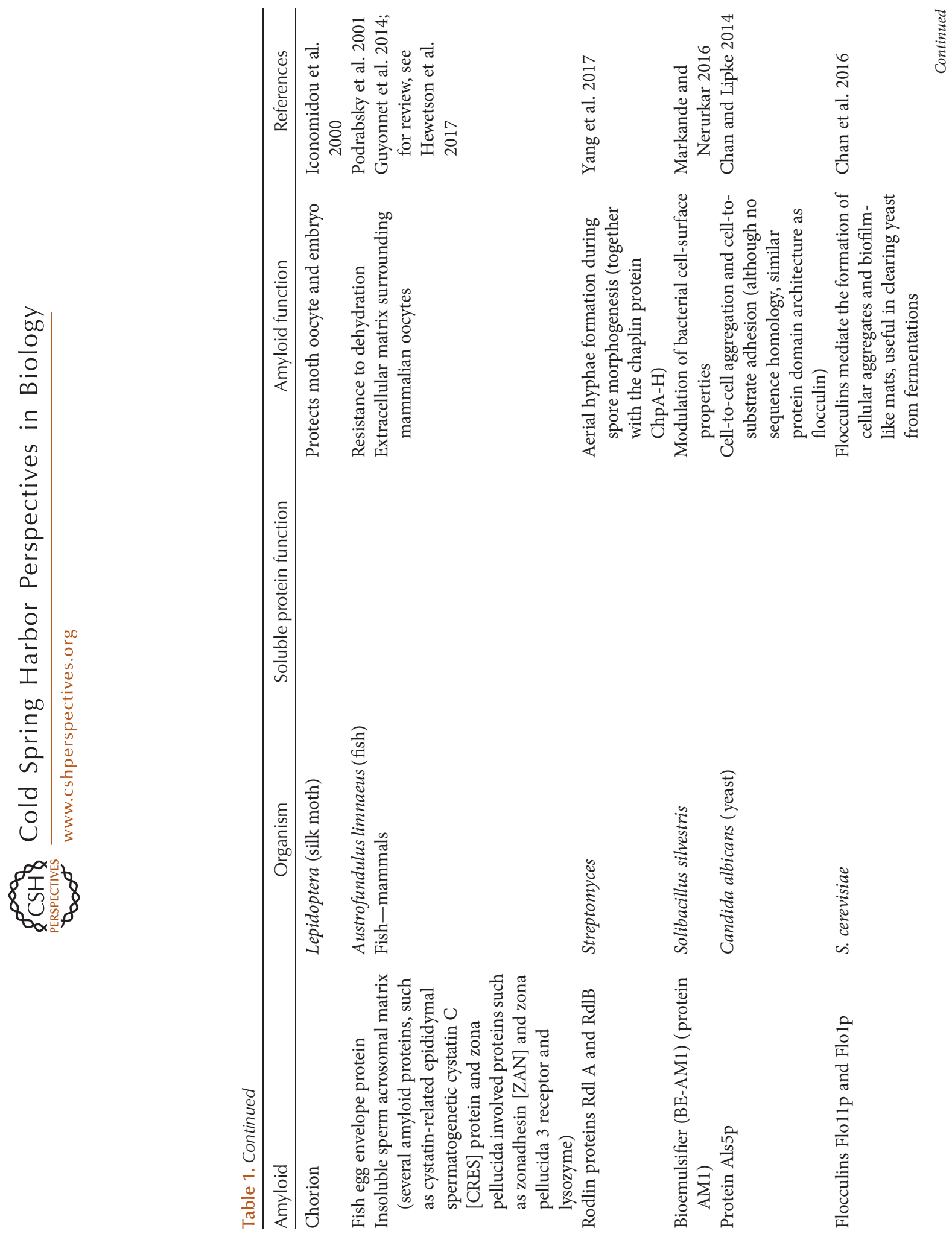
Functional Amyloids

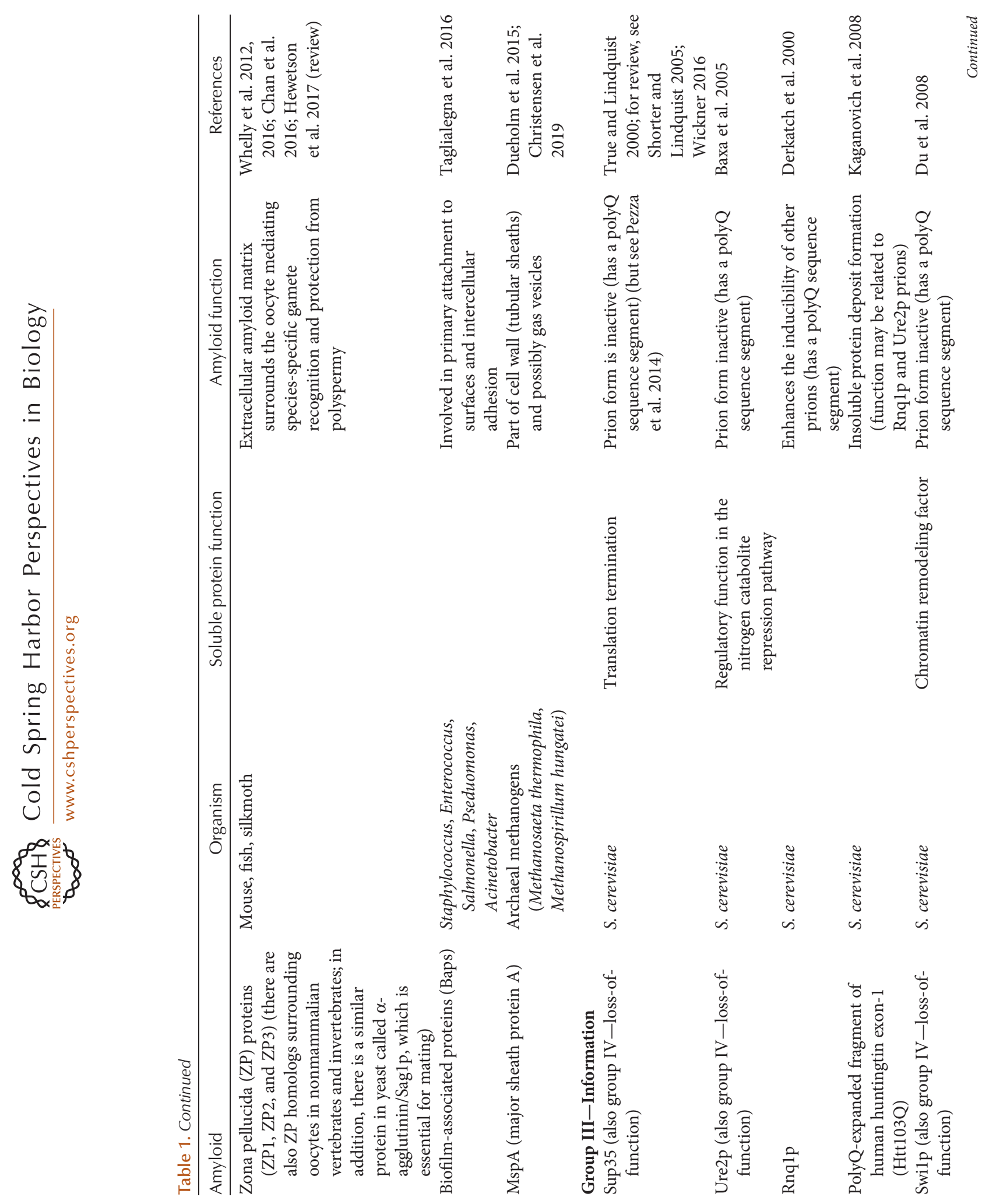


D. Otzen and R. Riek
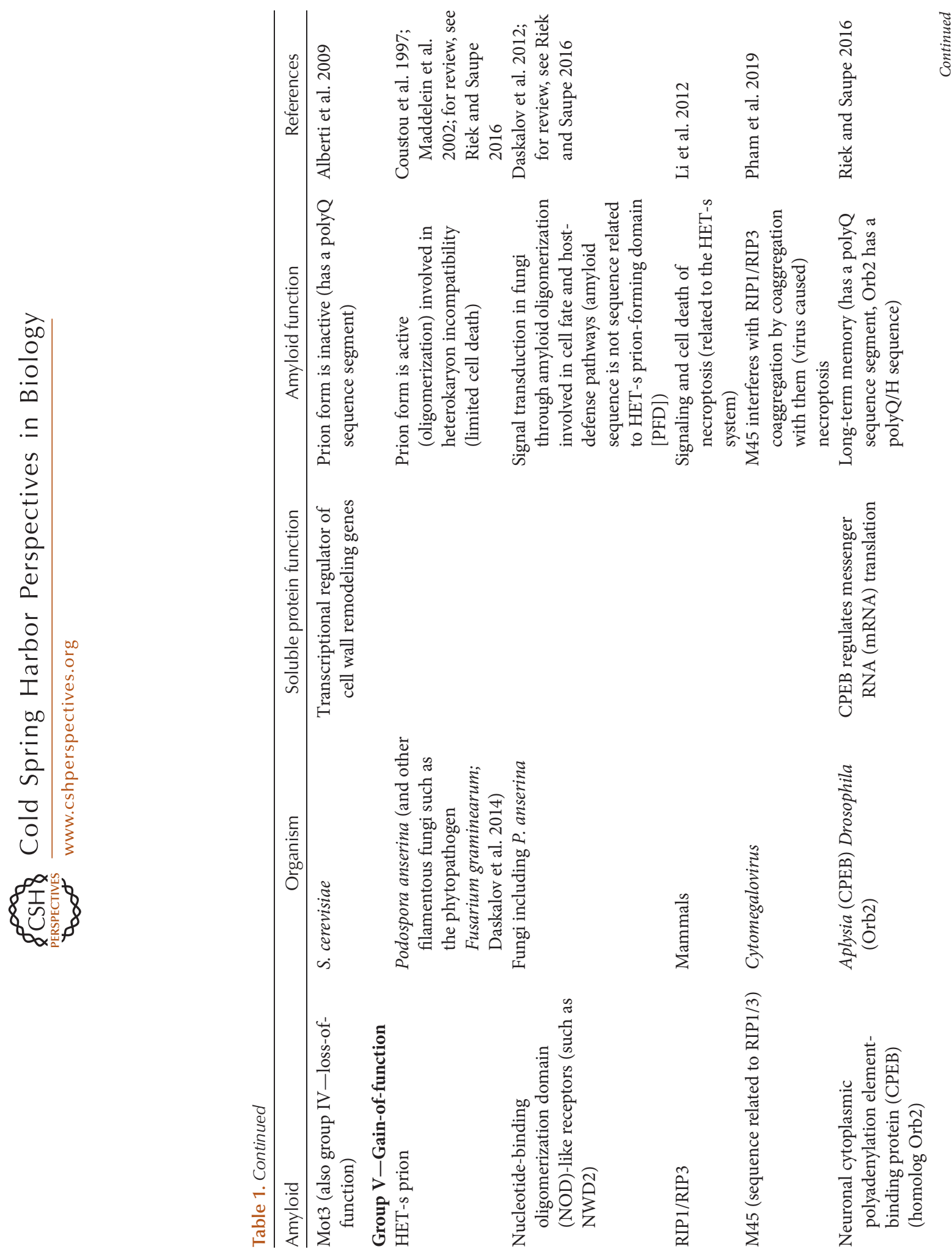
Functional Amyloids

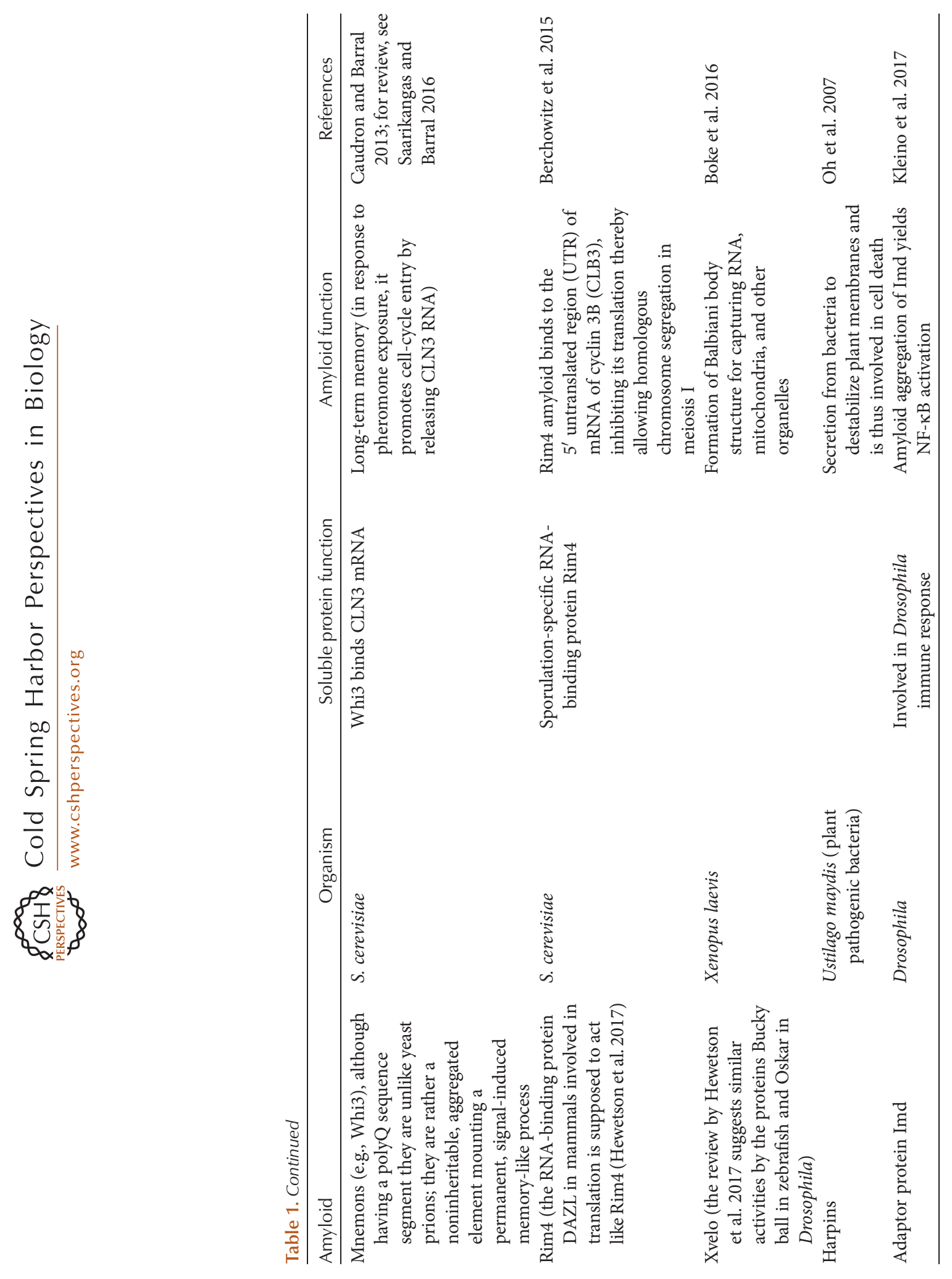


stored in an inert manner inside secretary granules ready for activation (see also below); the major basic protein (MBP), a highly toxic protein in eosinophils (a white blood cell type), which permeabilizes membranes unless sequestered in the amyloid state, and the bacterial poreforming Microcin E492 peptide. In addition, the yeast pyruvate kinase Cdc19 is stored in an inactive state as amyloid within stress granules when the yeast cell is in a resting state. This finding connects the membraneless granules to the functional amyloids, which are by definition a phase-separated functional state of a protein. To group II-structure-belong the amyloids that fulfill structural functions such as curli, involved in bacterial biofilm formation (see also below); chaplins, involved in aerial hyphae formation in streptomycetes; bacterial hydrophobins, which make a monolayer at a hydrophobic/ hydrophilic surface; and the eggshell protein chorion of silkworm and functionally related proteins in fish mammals that protect the oocyte and the developing embryo from a wide range of environmental hazards when in its amyloid state. Under group III-information-are amyloids involved in epigenetic inheritance and memory, which are all the functional prions including the HET-s prion of Podospora anserina involved in a primitive immune system (see also below), the yeast prions and alike (i.e., other poly-Gln [ polyQ] comprising amyloid proteins) such as the yeast mnemons and the aplysia cytoplasmic polyadenylation element-binding (CPEB) protein. The latter two have been implicated explicitly as information systems because their amyloid states are involved in (long-term) memory without having prion activity. For proteins in group IV-loss-of-function-amyloid formation leads to loss of their activity in the soluble state, including the yeast enzyme Cdc19, the termination factor sup35, and the toxic MBP protein. In contrast, proteins in group V-gain-of-function-are activated on amyloid formation in different ways. Examples include the HET-s prion, which induces an unand refolding of the HET-S prion protein accompanied by oligomerization and membrane penetration. Similarly, in the necroptosis-related amyloid system RIP1/RIP3, the process of het- ero-amyloid formation also gives rise to heterooligomers (i.e., soluble aggregates), starting a signaling pathway that eventually induces cell death.

In addition, there are many other potentially functional amyloids indicated by screens and amino acid sequence searches and comparisons summarized below in a separate paragraph (Danielsen et al. 2017). These findings indicate that the presented Table 1 is just the tip of the iceberg of functional amyloids.

Because the list of functional amyloids is large, this review will focus on a subset thereof: peptide hormone amyloids (group I-storage), curli (group II-structure), and the HET-s prion system (group III-information, and V-gainof-function). For other functional amyloid systems, we refer the reader to the references given in Table 1, which also includes, in part, reviews on the specific functional amyloids listed.

\section{FUNCTIONAL AMYLOIDS ARE WIDESPREAD IN BACTERIA}

Although functional amyloids are likely found in many different organisms, bacteria are particularly useful for "amyloid hunting" because of their relatively accessible cellular organization, both as single-species colonies on agar plates and in the more complex single- and multispecies biofilm communities. Early investigations therefore focused on bacteria. The approach taken is based on a combined approach with conformationally specific antibodies and the amyloid-binding dye thioflavin $\mathrm{T}$ and showed that $10 \%-50 \%$ of bacterial species sampled from diverse habitats (including freshwater lakes, drinking reservoirs, and wastewater-treatment plants) produced extracellular amyloid (Larsen et al. 2007). Already at this stage, it was obvious that these proteins performed a diversity of different tasks within the extracellular polymeric matrix. However, detailed further analysis was (and is) hampered by the extreme insolubility of these amyloids, which even resist boiling SDS solution, making it very difficult to mobilize and identify them by, for example, SDS-PAGE and mass spectrometry. The most efficient solvent for functional amyloid is the 
organic acid formic acid, which solubilizes, for example, curli from Escherichia coli at $80 \%-$ $100 \%$ concentration; other aggressive solvents such as trifluoroacetic acid (Jordal et al. 2009) and hexafluoroisopropanol (Cegelski et al. 2009) also have some effect. For example, to identify the amyloid produced by a Pseudomonas strain, it was necessary to isolate the SDS-insoluble fraction and dissolve it in $100 \%$ formic acid; subsequent partial sequencing by tandem mass spectrometry combined with full genomic sequencing finally identified the amyloid component FapC (Table 1) as well as the associated Fap operon. Recently, this approach has been systematized to carry out proteome-wide screening for functional amyloid on organisms whose genomes are available (Danielsen et al. 2017). More specifically, cell samples were exposed to $0 \%-100 \%$ formic acid (typically, in steps of $20 \%$ ), followed by lyophilization and SDSPAGE of the solubilized sample in buffer containing $8 \mathrm{M}$ urea. The bands running into the gel were then identified by mass spectrometry following tryptic in-gel digestion. Based on the rationale that conventionally soluble proteins will be equally soluble at all formic acid concentrations, whereas functional amyloid should only be solubilized at $80 \%-100 \%$ formic acid, amyloid proteins candidates were identified. In a next step, these candidates were evaluated by bioinformatics analysis. First, under the assumption that all bacterial, known functional amyloids are secreted, the list of hits were trimmed by eliminating those lacking sec-dependent signal peptides using programs such as the Signal 4.1 (Petersen et al. 2011). Second, the remaining sequences were analyzed by amyloid prediction algorithms mostly developed from the perspective of pathological aggregation. However, physical principles on which some of them are based can still be applied to functional amyloid because of shared structural features. These principles include secondary structure propensities, hydrophobicity, charge, hydrogen-bonding capacity, etc., as exploited in, for example, FoldAmyloid (Garbuzynskiy et al. 2010), Betascan (Bryan et al. 2009), and TANGO (Fernandez-Escamilla et al. 2004), which can be expanded to include sequence patterns
(Waltz [Maurer-Stroh et al. 2010]). Programs like AGGRESCAN, in contrast, base aggregation propensities of individual amino acids on data collected for variants of the Alzheimer peptide A $\beta$ (Conchillo-Solé et al. 2007). However, AGGRESCAN was used successfully together with TANGO and the program PASTA (Walsh et al. 2014) to identify amyloidogenic segments of a biofilm-associated protein in Staphylococcus epidermidis (Lembré et al. 2014) and the yeast cellwall protein Bgl2p (Bezsonov et al. 2013). When considering amyloidogenic candidates based on sequence, probably the single strongest indicator of a functional amyloid protein is the presence of imperfect repeats, each of which may represent a $\beta$-hairpin unit (as indicated in the predicted structure of the curli amyloid protein CsgA, see below). Besides CsgA, repeats have also been found in the functional amyloids FapC, MspA, and TapA as well as the Het-s prion (Table 1). Additional clues may be provided in the operon structure, which in the case of curli and related proteins contains ancillary proteins with specific tasks (see below). As the number of functional amyloids and their associated protein helpers continues to grow, sequence analysis will be put on an even firmer basis. Consequently, we can expect great advances in this area over the next few years. A more in-depth discussion of this topic is provided in Christensen et al. (2019). In summary, amyloids appear to be abundant.

\section{CURLI (GROUP II-STRUCTURE)}

The E. coli curli system is one of the protoypical example of a functional amyloid. It has revealed many striking features that turn out to occur in other functional amyloids. Consequently, it is worth focusing on this system in greater depth with an emphasis on these general features:

Amyloid as Biofilm Component and Adhesion

Curli fibrils are involved in biofilm formation by their integration into the extracellular matrix, increasing cell hydrophobicity (Boyer et al. 2007) and promoting surface attachment $(\mathrm{Pa}-$ war et al. 2005) for colonization and consolidation. They also mediate uptake of E. coli into 
eukaryotic host cells (Gophna et al. 2001; KaiLarsen et al. 2010) through interactions with host proteins such as fibronectin (Olsén et al. 1989) and the major histocompatibility complex (Olsén et al. 1998). Furthermore, both curli and the soluble component (CsgA) can induce production of proinflammatory cytokines in the E. coli sepsis reaction (Bian et al. 2000).

\section{Multicomponent Biosynthesis System}

The curli fibrils themselves are composed largely of the major amyloid protein CsgA but are anchored to the bacterial cell surface through the so-called nucleator protein CsgB. These are only two of the seven proteins involved in curli biogenesis, encoded by two divergently transcribed operons, $\operatorname{csg} B A C$ and $\operatorname{csg} D E F G$ (Hammar et al. 1995), whose intergenic region is subjected to extensive and complex regulation (Ishihama 2010). Initially discovered in Enterobacteriales (Collinson et al. 1991; Zogaj et al. 2003), these operons are now found in at least four different phyla (Dueholm et al. 2012). The tight regulation of the production and assembly of the curli fibrils is a hallmark distinguishing functional from pathological amyloid. This regulation avoids accumulation of potentially deleterious toxic oligomeric species, which are believed to be major culprits in neurodegenerative diseases (Andreasen et al.2015). More specifically, synthesis of the chaperones $\mathrm{CsgC}$ and $\mathrm{CsgE}$ is a precautionary measure to handle the highly amyloidogenic proteins CsgA and CsgB and escort them safely (i.e., monomerically) out of the cell (Nenninger et al. 2011; Evans et al. 2015). CsgC (and a structural homolog $\mathrm{CsgH}$, which is found in some Alphaproteobacteria, always next to $\operatorname{csg} A B$ genes) (Taylor et al. 2016), mainly inhibits primary nucleation of CsgA by suppressing formation of intermediate species on the aggregation pathway (Taylor et al. 2016). Similarly, CsgE completely inhibits CsgA fibrillation at 1:1 molar ratios (Nenninger et al. 2011). The remaining three proteins work as a curli assembly factor $(\mathrm{CsgF})$, a transcriptional regulator $(\mathrm{CsgD})$, and a multimeric outer membrane protein (CsgG) (Goyal et al. 2014). The pore constructed by CsgG provides an exit path out of the outer membrane. Exit specificity is provided by CsgE, which forms a dynamic complex with CsgG (Goyal et al. 2014), allowing it to recognize the 22-residue prosequence found on the amino terminus of both CsgA and CsgB (it also recognizes other proteins if they are provided with this residue, leading to a very convenient CsgG-specific export pathway (Sivanathan and Hochschild 2013). All Csg proteins except the regulator CsgD have signal sequences and are transported across the inner membrane through the Sec translocase.

\section{Multiple Repeats and a Nucleator-Elongator Partnership}

The two curli fiber proteins, CsgA and CsgB, are homologs that share $49 \%$ sequence similarity. Importantly, they both contain five imperfect repeats (R1-R5), a simple but effective means to drive rapid fibrillation. The two sets of repeats are similar but not identical $\left(\mathrm{SX}_{5}\right.$ QXGXGNXAX ${ }_{3} G$ in CsgA versus $\mathrm{AX}_{3} \mathrm{QXX}_{2}$ $\mathrm{NXAX}_{3} \mathrm{~N}$ in CsgB's four amino-terminal repeats). The carboxy-terminal repeat of $\mathrm{CsgB}$, on the other hand, has four positive charges and helps tether $\mathrm{CsgB}$ on the cell surface (Hammer et al. 2007). The Gln and Asn residues in CsgA are important in stabilizing the amyloid structure (Wang and Chapman 2008). When the repeats are expressed as isolated peptides, three out of the five repeats (R1/R3/R5 in CsgA and R1/R2/R4 in CsgA) fibrillate spontaneously in vitro, and it is likely that the sheer number of repeats in the full-length protein is a powerful driving force for fibrillation. $\mathrm{CsgB}$ and $\mathrm{Csg} \mathrm{A}$ cooperate closely to form curli. Although both CsgA and CsgB both fibrillate spontaneously in vitro (Chapman et al. 2002; Hammer et al. 2007), mutants lacking either protein do not form curli (Hammar et al. 1996). The current understanding is that $\mathrm{CsgB}$, anchored on the outer membrane, binds to CsgA and kick-starts (nucleates) its fibrillation on the bacterial cell surface. This eliminates the lag phase that is thought to be the kinetic bottleneck under physiological conditions. In the absence of CsgB, CsgA simply diffuses away from the cell surface, diluting out and thus rendering amyloidogenesis much less prob- 
able. A powerful vindication of this is the phenomenon of interbacterial complementation, in which CsgA produced from cells lacking CsgB can assemble into fibrils on nearby CsgB-producing (though CsgA-lacking) cells (Hammer et al. 2007). Besides ensuring local production of curli fibrils, this assisted nucleation step also minimizes the risk of forming cytotoxic oligomeric species, which otherwise often accumulate under conditions favoring amyloid formation. The robust nature of the curli system has allowed it to be harnessed for purposes as diverse as screening systems for detecting amyloidogenic protein sequences (Sivanathan and Hochschild 2013), biofilms with tailor-made ligand-binding properties (Nguyen et al. 2014), and underwater glue (Zhong et al. 2014; see review by Christensen et al. 2019).

\section{An Intrinsic Drive to Nucleation Reflected in} the Sequence

Although many globular proteins can form amyloids, they typically require harsh and partially denaturing conditions to accomplish this and then often fibrillate from a partially structured state (Giehm and Otzen 2013). In contrast, functional amyloid such as CsgA can fibrillate under a very broad range of $\mathrm{pH}$ and ionic strength conditions, emphasizing its strong drive to form amyloids (Dueholm et al. 2011). Monomeric CsgA is largely unstructured and only forms $\beta$-sheet structure on fibrillation, suggesting that folding and amyloid formation are closely coupled (Dueholm et al. 2011). The final fibril structure has all the hallmarks of a cross- $\beta$-sheet structure according to both X-ray fiber diffraction (Dueholm et al. 2011) and solid-state nuclear magnetic resonance (NMR) (Shewmaker et al. 2009), but the NMR data also suggest formation of stacked $\beta$ helical subunits. This was confirmed in computational predictions of the CsgA and FapC structures, which combined molecular simulation with information obtained from large sequence databases. Because by definition a functional amyloid is the product of evolution (compared with their pathological counterparts), a comparison between homologs of CsgA and FapC provides useful structural constraints for potential resi- due-residue contacts within the amyloid structure. When combined with molecular simulation, these constraints led for both proteins to a $\beta$-helical structure in which the individual repeats (five for CsgA and three for FapC) stack as $\beta$-hairpin structures perpendicular to the $\mathrm{pu}-$ tative fibril axis (Fig. 2A,B). It seems very straightforward to stack multiple monomers to obtain a fibril structure, making the monomer, which in itself could be considered an assembly of individual amyloidogenic repeat units-the minimal amyloid unit. The CsgA model remains ambiguous because the handedness of the $\beta$-helix (left vs. right) is not resolved and there are multiple ways to arrange intermolecular contacts. Nevertheless, the two models may serve as a starting point for additional studies.

\section{Parallels to Other Systems}

The Fap (functional amyloid in Pseudomonas) system (recently reviewed in Rouse et al. 2018) is evolutionarily younger than the curli system (Dueholm et al. 2013a) but the two systems are similar at multiple levels. Overexpression of Fap strongly increases biofilm formation (Dueholm et al. 2013b) and increases biofilm stiffness and hydrophobicity (Zeng et al. 2015). A functional genomics study showed that deletion of the major Fap protein FapC led to a very marked reduction in Pseudomonas aeruginosa's ability to infect $C$. elegans, indicating a role for Fap fibrils in virulence. The operon $f a p A B C D E F$ encodes six proteins (Dueholm et al. 2010) within multiple classes of Proteobacteria, in addition to FapC, including the FapC homolog FapB, which is likely a nucleator. Both FapC and FapB have three imperfect repeats, but these repeats are 1227 residues longer than those of CsgA/B and are connected by linkers of variable length, unlike CsgA/B's tight four- to five-residue $\beta$-turns between and within repeats. Remarkably, the FapC repeats completely lack aromatic residues that can otherwise stabilize amyloid structures significantly (Gazit 2002), indicating a more minimalistic approach to amyloid formation. The gradual increase in FapC homologs in the sequence database since the first computational prediction of the CsgA structure has recently 
A

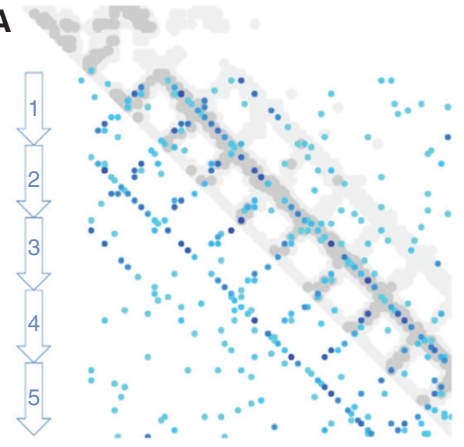

B

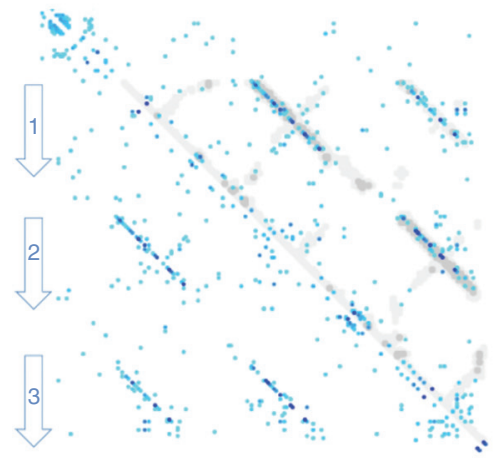

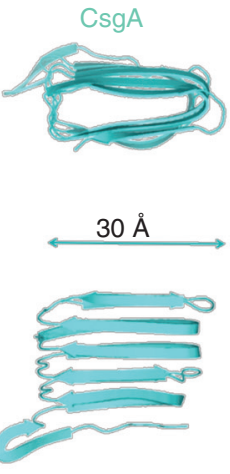

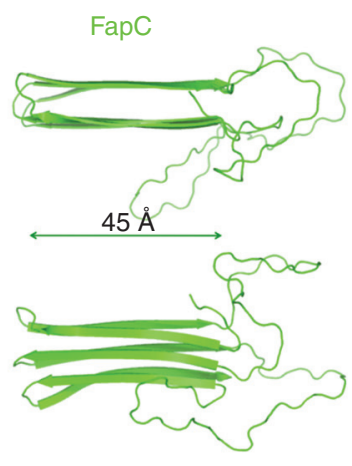

C

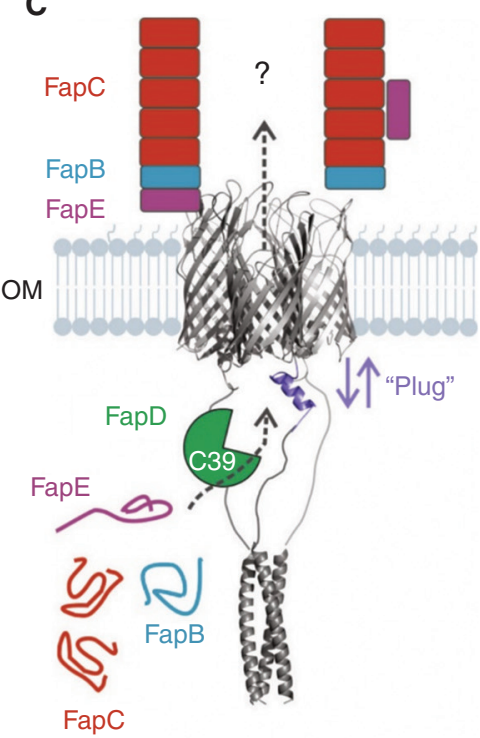

IM

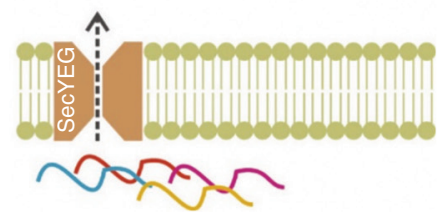

Figure 2. Structural models of the monomeric units of CsgA and FapC in Fap and curli fibrils and a model for Fap biogenesis. The models are computed by combining inter-residue constraints (based on sequence covariation) with molecular simulations. Plot showing predicted contacts between $(A) \mathrm{CsgA}$, and $(B)$ FapC residues based on sequence data. The individual amyloid repeats of the two proteins are indicated by arrows. The darker the blue dots, the greater the coevolutionary strength. Distances calculated from the resulting coordinate file are depicted with gray spheres. The model of CsgA is based on data in Tian et al. (2015), with the model of the FapC core highlighting the three repeats and the unstructured linker regions (figure reprinted from Rouse et al. 2018 under the terms of the Creative Commons Attribution License CC BY). (C) Proposed model for how Fap fibrils are produced in Pseudomonas. All Fap components enter the periplasm via the Sec pathway. FapB (blue), FapC (red), and FapE (magenta) remain unfolded in the periplasm. The membrane protein FapF (gray) forms a stable trimer within the outer membrane (OM), although its amino-terminal coiled-coil domain extends into the periplasm. The channel is gated by plugs (violet) whose conformational changes permit substrate secretion through the OM. For clarity, only one plug is shown. FapD (green) proteolytic activity is essential for secretion. FapE may associate in different ways with the FapC/B fibrils extending from the surface. IM, Inner membrane (figure reprinted from Rouse et al. 2018 under the terms of the Creative Commons Attribution License CC BY).

made it possible to propose a model for the FapC structure, which predicts that the linker regions do not insert into the amyloid core, owing to the lack of predicted direct contacts (Rouse et al. 2018). The ensuing model (Fig. 2) shows a two-sided $\beta$-helix with a 4.5 -nm fibril core (wider than CsgA's $3 \mathrm{~nm}$ ) and excluding the carboxy-terminal Cys-rich motif. Interestingly, complete removal of all three repeats from FapC leads to a variant that aggregates extremely slowly and is significantly less stable than wild-type FapC (Rasmussen et al. 2019), but nevertheless is able to be arranged in an amyloid structure. It is unclear whether it would be possible to form weak contacts between wild-type FapC through these amyloidogenic linker regions; future structural studies may resolve this. 
FapA's function is unclear, but its serendipitous deletion led to formation of fibrils composed almost entirely of FapB (Dueholm et al. 2013b), suggesting that FapA may chaperone Fap fibrillation. FapE is probably transported across the outer membrane because small amounts have been found in mature Fap fibrils (although its mode of incorporation into fibrils remains unclear); it may be able to interact with FapC, and aid its export, through mutually conserved Cys residues in both proteins' carboxyl termini (Dueholm et al. 2013b). FapD is suggested to be a cysteine protease based on its sequence (Dueholm et al. 2013b), indicating a role in processing of Fap proteins. FapF was predicted to be a $\beta$-barrel membrane pore protein (Dueholm et al. 2013b), in good agreement with a proteomics study showing it to be membrane-associated (Manara et al. 2012). Both observations were confirmed when the structure of FapF, solved by crystallography, revealed a trimeric $\beta$-barrel channel gated by a helical plug and connected to a (predicted) extended coil-coil domain in the periplasm (Fig. 2C) (Rouse et al. 2017). The periplasmic domain is vital for FapC secretion (probably by regulating gating) and FapF trimerization (Rouse et al. 2017). Besides this domain, FapF differs significantly from its curli counterpart CsgG in several ways: FapF forms three parallel gated channels via each monomer (nine CsgG monomers go together to form one channel) and does not recognize a specific targeting sequence (unlike CsgG's N22 sequence).

Thus, comparison between the Csg and Fap systems have unearthed intriguing similarities and differences. With the expected rapid increase in the rate of identification of functional amyloid systems thanks to proteome-wide approaches to detect amyloid, we can expect many more exciting discoveries and revelations in the future.

\section{PEPTIDE HORMONE AMYLOIDS IN THE FORMATION OF SECRETORY GRANULES (GROUP I-STORAGE)}

Eukaryotic cells have specialized pathways to transport secretory proteins/peptides to the extracellular space (Kelly 1985, 1987). These include the formation of membrane-enclosed secretory granules in which peptide hormones (or other proteins such as the MBPs) are stored at high concentrations (Fig. 3) (Kelly 1985; Arvan and Castle 1998; Dannies 2001; Soragni et al. 2015). Granular storage allows the cells to store a large quantity of the hormone/protein until triggered by an outside signal, leading to hormone/protein release rates far in excess of their synthesis rates. The granules are generally composed of a single hormone peptide/protein species stored in an amyloid state (Maji et al. 2009a). The amyloid state confers semi-autonomous properties in terms of hormone sorting, secretory granule formation, inert hormone storage, and hormone release, minimizing the need for dedicated cell machinery. Indeed, if the prohormone provaspressin is expressed in fibroblast and other cells lacking an endocrinespecific machinery, dense granule-like structures form spontaneously (Beuret et al. 2004). In the following, the potential properties of amyloids in the sorting, granule formation, storage, and release of hormones are discussed (Fig. 3).

The Timing and Location of Amyloid Aggregation in the Golgi

Because amyloid aggregation of a small peptide is sensitive to the sequence and chemical modifications of the peptide, there are multiple ways in which processing could initiate aggregation. Some of the prohormones have highly hydrophilic sequence segments that interfere with aggregation. Other prohormones capture the aggregation-prone hormone within the $3 \mathrm{D}$ structure as shown for provasopressin (Fig. 3A). Amyloid aggregation can also be controlled by prohormone concentration. As the $\mathrm{pH}$ decreases from the endoplasmic reticulum (ER) ( $\mathrm{pH} \sim 7.4)$ to secretory granules ( $\mathrm{pH} \sim 5.5$ ), hormone aggregation may be controlled by $\mathrm{pH}$ as suggested for many hormones (Maji et al., 2009a) and exemplified for $\beta$ endorphins. The 3D solid-state NMR structure of $\beta$-endorphin amyloids comprises a protonated Glu in a hydrophilic core of the $\beta$-solenoid, requesting a protonation of the Glu side chain (with a solvent-exposed pI of ca 4.3) before aggregation can occur (Verasdonck 2017). Further- 
D. Otzen and R. Riek

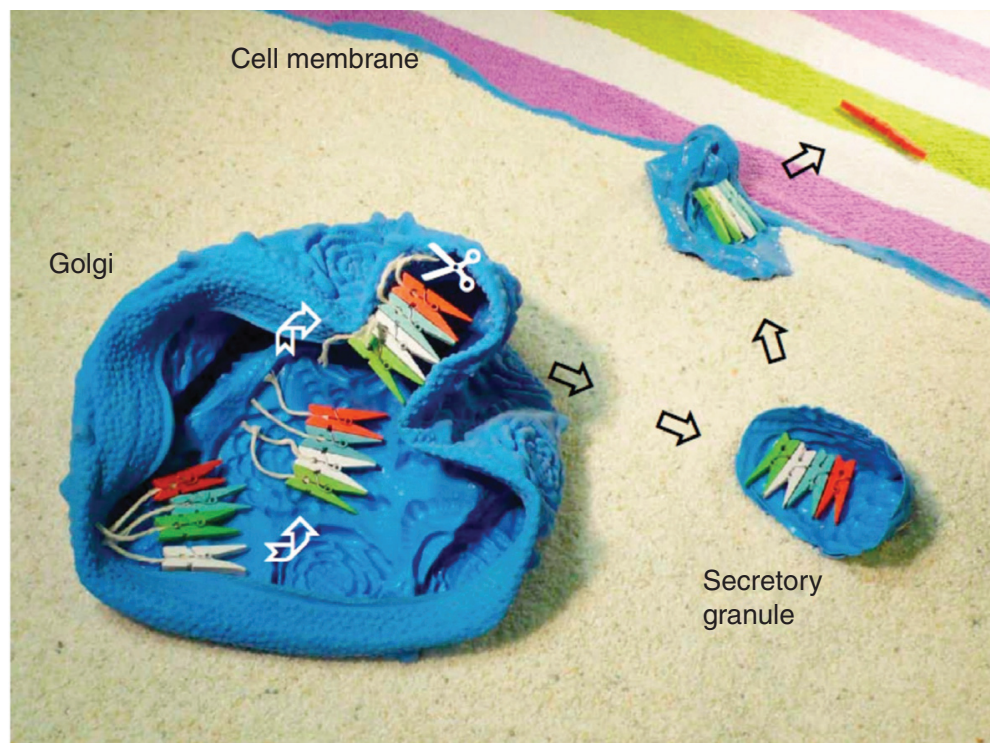

Figure 3. The amyloid activities in the secretory granule biogenesis. The amyloid state of peptide hormones in secretory granules (shown by an alignment of several clothes pins) may explain the processes of granule formation, selection, storage, and release of hormones in the granules. It is suggested that in the Golgi (shown as a blue bathing cap), the amyloid aggregation of the prohormone (shown by individually colored clothespins with a tail) is initiated spontaneously above a critical prohormone concentration or/and in presence of helper molecules such as glycosaminoglycans (GAGs). This may occur in parallel with prohormone processing (indicated by scissors) that could also initiate the aggregation. Because formation of amyloid fibrils is highly sequence-specific, amyloid aggregation of the (pro)hormone is selective. This excludes nonaggregationprone constitutively secreted proteins and yields granule cores composed of single hormones or multiple distinct hormone coaggregates only. Because the amyloid entity is usually able to interact with membranes (shown in blue), the hormone amyloid is spontaneously coated with membranes during the aggregation process, followed by the formation of granules. Thanks to the high stability of amyloids, mature secretory granules can exist for extended periods. On stimulation, secretory granules are secreted and release monomeric, functional hormone (indicated by an extended red stick) in a controlled manner. The scissors indicate the convertases. The cytoplasm is shown as sand, the extracellular space as a bath towel. The red colored stick represents the released soluble hormone. (From Seuring et al. 2013; reprinted with permission from the authors.)

more, there is the possibility of controlling aggregation through the presence of helper molecules inside secretory granules such as GAGs, which can stabilize the amyloid conformation (Maji et al. 2009b).

\section{Hormone Sorting in the Golgi}

The formation of amyloid fibrils on prohormone processing into hormone by convertases is highly sequence-specific, so that once initiated, the amyloid aggregation of the hormone is self-selective, yielding granule cores composed of specific hormones only. Specific coaggregation of some hormones might be possible (Maji et al. 2009b) because amyloid peptides are able to cross-seed (Han et al. 1995; Giasson et al. 2003), which would also eventually result in a defined hormone release ratio.

\section{Membrane Formation}

The hormone amyloids are surrounded by membrane as they separate from the Golgi. There are many examples to suggest that membrane binding is an inherent property of amy- 
loid aggregates (Sparr et al. 2004; Gellermann et al. 2005) and so formation of a membrane around the hormone aggregate may be a spontaneous event.

\section{Hormone Storage}

After initiation of aggregation and sorting of the peptides into specific secretory granule cores, the amyloid structure provides the most dense packing possible (Nelson et al. 2005), both excluding nonaggregation-prone constitutively secreted proteins and providing an extremely stable storage system. Within this context, it is noteworthy that also the toxic MBP is stored in an amyloid-like state inside secretory granules of the white blood cell eosinophils (Soragni et al. 2015). Once secreted, the amyloid cores rapidly decompose, releasing MBP oligomers that are toxic to both the pathogen as well as host cells because of their ability to bind to and disrupt membranes.

\section{Hormone Release}

Finally, on receiving the appropriate signal, the granules are secreted and the amyloid structure of the hormone disaggregates in a controlled fashion to release monomeric, functional hormone. Disassembly of $\beta$-endorphin is governed by a combined change in $\mathrm{pH}$, buffer composition, and hormone dilution. The $\mathrm{pH}$ change from $\mathrm{pH} 5.5$ (secretory granule) to $\mathrm{pH} 7.4$ (blood) deprotonates the Glu8 located inside the $\beta$-solenoid core structure, driving the release of hormone at the end of fibrils; consistent with this, the E8L mutant does not undergo $\mathrm{pH}$-dependent disassembly (Verasdonck 2017). Rapid disassembly of $\beta$-endorphin amyloids is observed when changing the buffer composition from one corresponding to a secretory granule relevant (phosphate) to one corresponding to blood (phosphate-free, i.e., bicarbonate) (Nespovitaya et al. 2016). Based on the 3D structure of $\beta$-endorphin amyloids, we attribute this effect to the polyanionic property of phosphate, which binds to the five positively charged Lys sides located on the surface of the $\beta$-solenoid structure and thus limits intermolecular repulsion (Veras- donck 2017). In addition, extracellular chaperones may be involved in disaggregation.

It is apparent that the formation and stability of hormone amyloids, the intracellular localization of formation as well as amyloid disassembly have all been evolutionarily optimized by elegant exploitation of their multifaceted properties. However, there are also cases of disease-associated aggregations of hormones. In diabetes insipidus, more than 70 familial mutations within the provasopressin hormone are known (Beuret et al. 2017). A subset of these familial mutants was studied in cell lines (Birk et al. 2009). The mutant provasopressin was retained in the ER where it formed amyloid fibrils, accompanied with ER stress and cell death. This is consistent with diabetes insipidus, for which loss of vasopressinergic neurons was observed in postmortem biopsies (Green et al. 1967). The combined results suggest that familial diabetes insipidus belongs to the group of neurodegenerative amyloid diseases with the distinction that aggregation does not occur extracellularly or in the cytosol, but in the ER lumen. Furthermore, a recent study by Beuret et al. (2017), linked functional amyloid formation with disease-amyloid formation by a detailed mutant-based structure-activity relationship in cell studies. They found that the provasopressin amino acid sequence segments required for secretory granule formation (i.e., the nine amino acid residues segment of vasopressin and the carboxy-terminal glycopeptide) are also the ones involved in amyloid aggregation within the ER. This is a direct demonstration that amyloid aggregation at the wrong place is toxic in the case of the hormone vasopressin.

In addition to diabetes insipidus and several cancers (such as endocrine tumors), extracellular hormone amyloids (such as calcitonine, insulin, growth hormone, etc.) are currently attributed to hormonal overproduction (Westermark et al. 1977). Although they are considered a pathological hallmark of the cancers, these amyloids are believed to be nontoxic. Similarly, extracellular possibly nontoxic amyloid aggregates of the MBP stored functionally in an amyloid state in secretory granules of eosinophils are found in a number of eosinophilic diseases, 
including Well's syndrome, having excessive proliferation of eosinophils (Soragni et al. 2015).

\section{THE HET-s/S PRION SYSTEM (GROUP III- INFORMATION AND V-GAIN-OF- FUNCTION)}

Fungi have the unusual ability to undergo somatic cell fusions. When in close proximity, two individuals belonging to the same species will grow toward each other, fuse, and mix their cytoplasmic content forming a heterokaryon. Yet, these mixed cells will usually undergo a programmed cell death observed as a demarcation line between the strains (Glass and Dementhon 2006; Pinan-Lucarré et al. 2007). This phenomenon is termed heterokaryon incompatibility. Viable fusion can only occur between strains that are compatible, meaning that they harbor appropriate alleles at particular recognition loci that are termed het loci. Thus, heterokaryon incompatibility can be regarded as a self-/nonself-recognition mechanism or a primitive immune system, whose proposed function is to limit cytoplasmic mixing to genetically similar strains. Uncontrolled cytoplasmic mixing can lead to infection with deleterious genetic elements like viruses (Pearson et al. 2017). The $P$. anserina population can slip into two types of strains, the strain bearing the het-s (lowercase s) allele and those bearing the het-S (uppercase S) allele; het-s and het-S are two allelic variants of the same gene, and the corresponding HET-s and HET-S prion proteins are 95\% identical (Turcq et al. 1991). Het-s and het-S strains are incompatible and undergo cell death when they fuse, but only if the HET-s prion protein is aggregated into an amyloid. Furthermore, the amyloid is classified as a prion (proteinaceous infectious agent) because it transmits its amyloid state to a new het-s host on cell fusion. The "infected" het-s host will show a heterokaryon incompatibility reaction if fused with a het-S colony. Thus, the amyloid state is an information carrier (group III-information) with signaling capacities (group V-gain-of-function). Detailed structure-activity relationship studies, including the structure determination of two of the three players, give detailed insights into the mechanism of action of the HET-s/HET-S prion protein system.

HET-s is a two-domain protein comprising an amino-terminal well-folded domain, termed HeLo, responsible for cell death execution in incompatibility (Seuring et al.2012) and a carboxyterminal prion-forming domain (PFD) comprising residues 218-289 (Balguerie et al. 2003; Greenwald et al. 2010). The HET-s-PFD is both necessary and sufficient for amyloid formation and prion propagation. Although flexible in the monomeric state, the PFD forms a $\beta$-solenoid structure in its amyloid state (Fig. 4) (Wasmer et al. 2008). It contains two 21-residue imperfect repeats, each forming one layer of the $\beta$-solenoid structure (Ritter et al. 2005), leading to a stacking arrangement in which alternating charged amino acid residues along the fibril surface form salt bridges. The pairing of these repeats guarantees the presence of a single low-energy fold without detectable polymorphism in HET-s fibrils over the entire physiological range of conditions (Riek and Saupe 2016) (note: under nonphysiological conditions such as $\mathrm{pH} 3$, the PFD forms a noninfectious amyloid that has a distinct conformation from the infectious one, an example of fibrillar polymorphism [Wasmer et al. 2009]). This illustrates the evolutionary optimization of the amino acid sequence for the $\beta$-solenoid structure through a gene duplication event that subsequently developed into two complementary repeats (Wasmer et al. 2008). Evolutionary conservation of the $\beta$-solenoid fold is further supported by a structure-based amino acid sequence comparison in different HET-S/s homologs (Daskalov et al. 2014). The prion formation and propagation by the HET-s PFD can also occur in a heterologous host, like yeast, indicating that no species-specific cofactors are required for prion propagation (similar to the hormone systems discussed above) (Taneja et al. 2007). Thus, the $\beta$-solenoid structure itself is the infectious entity of the HET-s prion and thus the information carrier is the amyloid structure.

Furthermore, the prion form of HET-s is not toxic to cells, but its interaction with HET-S is. Based on the work by Saupe and Riek (Greenwald et al. 2010; Mathur et al. 2012; Seuring et al. 2012), the following mechanism of action 

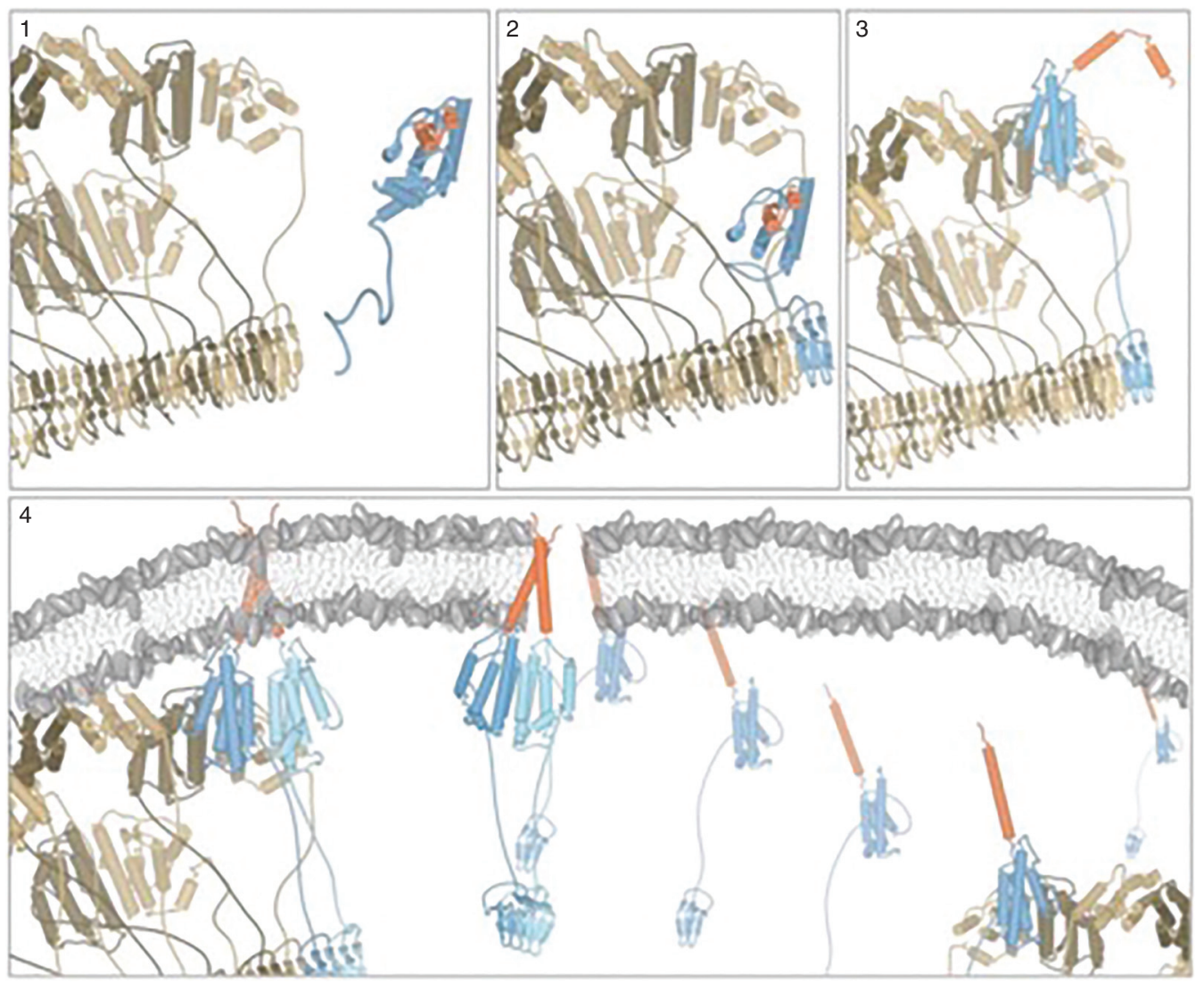

Figure 4. Proposed mechanism for the generation of toxicity by the HET-s prion/HET-S system. (1) In the fusion cell, HET-S (in blue with a red transmembrane segment) encounters the $\beta$-solenoid structure of the HET-s prion (in brown). (2) HET-S binds to the $\beta$-solenoid structure through its own prion-forming domain (PFD) segment, itself adopting the $\beta$-solenoid structure. The structural overlap of the HeLo domain and the PFD causes a partial unfolding of the HeLo domain of HET-S, represented here by the transition to a random coil conformation of its three carboxy-terminal helices. (3) The destabilized HeLo domain of HET-S then expels its amino-terminal transmembrane segment (residues 1-34, in red). (4) The exposed transmembrane segment targets the activated HET-s/HET-S complex to the membrane where it is able to penetrate the membrane through the formation of a transmembrane helix and oligomerization. Membrane integrity is thus disrupted by hole-like structures triggering cell death. The model for the HET-s fibril was created from the PFD fibril structure (Wasmer et al. 2009) and the HeLo domain structure (Greenwald et al. 2010) with an unwinding of the last three helices of the HeLo domain (residues 177-222) to make space for the HeLo domains around the fibril. The HET-s HeLo domains are depicted as dimers between adjacent monomers in the fibril, but these are speculative and it should be emphasized that the structures of the HeLo domains of HET-s and HET-S, in the context of a fibril, are not known except that they lose tertiary structure (i.e., become more molten globule-like), and also locally lose secondary structure around residues 190-220 (Wasmer et al. 2009).

is found (Fig. 4): Cell death on fusion between a strain having HET-s prions and another strain having HET-s prion protein is triggered when the prion templates conversion of the HET-S PFD region into the $\beta$-solenoid fold. The incorporation of HET-S into the $\beta$-solenoid of HET-s drives refolding of the HET-S HeLo domain. This exposes an amino-terminal transmembrane helix, which inserts into the cell membrane and oligomerizes, leading to pore formation and cell death. In this system, the amyloid fold is thus used as a triggering device that induces un-/re- 
folding and activation of the HeLo pore-forming domain. The conformational switch relies on the partial sequence overlap between the $\beta$-solenoid and HeLo domain (Greenwald et al. 2010). Remarkably, it appears that the HeLo domain is evolutionarily related to the cell death execution domain of a protein termed MLKL, responsible for execution of necroptotic cell death in mammals. Furthermore, upstream of MLKL activity is the RIP1/RIP3 hetero-functional amyloid system that on hetero-aggregation induces a downstream signal with the membrane incorporation of the MLKL protein yielding cell death through membrane permeabilization similar to the case of the HET-s/HET-S system (see Table 1). Building on these observations, it has been proposed that the HET-s PFD sequence segment and other amyloid segments are common homo- and hetero-oligomerization domains involved in cell fate and both plant and animal host-defense pathways in fungi such as the nucleotide-binding oligomerization domain (NOD)-like receptors, which are signal-transducing ATPases (so-called STAND proteins) (Daskalov et al. 2012; Riek and Saupe 2016).

\section{FUNCTIONAL VERSUS DISEASE- ASSOCIATED AMYLOIDS}

Given the existence of both functional and disease-associated amyloids, it is obvious-particularly in this collection on proteostasis-to ask: what makes amyloid functional and what makes it toxic? Here, we discuss the following hypotheses: (1) Disease-associated amyloids are toxic and therefore they must structurally differ from functional amyloids. (2) The aggregation of functional amyloids is highly controlled and avoids toxicity. (3) The aggregation of functional amyloids is so fast that no toxic oligomers accumulate. We find there is support for all three scenarios, which are not mutually exclusive.

Inherent Differences in Amyloid Structure: Exposure of Hydrophobic Surface Area and Fibrillary Polymorphism

Let us compare the 3D structures of two functional amyloids (HET-s and $\beta$-endorphin) with three amyloids associated with disease $(\mathrm{A} \beta[1-$ 42], $\alpha$-synuclein, and tau) (Wasmer et al. 2008; Seuring et al. 2012; Wälti et al. 2016; Verasdonck 2017; Guerrero-Ferreira et al. 2018). It is evident that all five amyloids are stabilized by hydrophobic contacts in the core structure and intermolecular backbone and side-chain, hydrogenbond formation along the cross- $\beta$-sheet (Fig. 5). Although the HET-s(218-289) amyloid shows polar surfaces and almost no hydrophobic patches at the surfaces, $A \beta(1-42), \alpha$-synuclein, $\beta$-endorphin, and tau amyloids expose some hydrophobic regions. In the case of $A \beta$ (1-42), tau, and $\alpha$-synuclein amyloids, these hydrophobic surfaces may perturb cell proteostasis through unspecific capture of other hydrophobic biomolecules, including proteins, chemically reactive small molecules, chaperones, and in particular lipids and lipid membranes. The latter potentially toxic interaction between lipid membrane and amyloids has been studied extensively (Chiti and Dobson 2006; Reynolds et al. 2011). As previously mentioned, the repetitive structure encountered at subnanometer resolution for both amyloid and lipid membrane may yield much higher apparent mutual affinities-a property that is unique for amyloids among the protein fold universe. In addition, $A \beta(1-$ $42)$, tau, and $\alpha$-synuclein amyloid structures contain frustrated structural segments, so called because the amino acid sequence was not evolved for this structural state and is forced into an energetically unfavorable conformation (Wolynes 2015). For $A \beta(1-42)$, the backbone structure of F19-D23 is sterically frustrated, $\alpha$ synuclein fibrils show a hydrophilic core with a hole as well as three Lys residues close in space, whereas the tau fibrils comprise several polar and charged interactions within the core of the structure and a rather large surface/volume ratio. Because frustrated areas as well as hydrophobic surface patches are recognized by chaperones or other proteostasis machinery (such as nascent chain-binding proteins), amyloid structures can simply titrate out the available proteostasis protein population in unproductive binding complexes with predictably deleterious consequences for cell proteostasis (see also Jayaraj et al. 2019). Another level of structural complex- 
ity with disease-associated amyloids is fibrillary polymorphism (Pedersen et al. 2010); the existence of many structurally distinct amyloid states for both $A \beta$ (Petkova et al. 2005) and $\alpha$ synuclein (Peelaerts et al. 2015) is in stark contrast with functional amyloids that show a single monomorph, at least under physiological conditions and in some cases also under more extreme conditions (Dueholm et al. 2011). This finding is not surprising. The amino acid sequences of the functional amyloids have evolved toward the amyloid state, although this is not the case for the disease-associated amyloids.

\section{Tight Control of Aggregation}

Both for hormone amyloids and bacterial amyloid, aggregation appear to be tightly controlled. This involves both control of the physical-chemical environment (such as $\mathrm{pH}$, buffer composition, small chemical molecules, and amyloid peptide/protein concentration) and the use of ancillary proteins (e.g., enzymatic processing by convertases from prohormone to hormone and chaperones that inhibit periplasmatic aggregation of CsgA/FapC and direct them toward the exit channel). Similar observations have been made for Pmel17, whose aggregation into amyloid is responsible for the deposition of the pigment melanin (Table 1) (Watt et al. 2013). Pmel17 aggregation has many levels of control: the protein must first pass through multivesicular, endosomal compartments before it can be proteolytically processed by a proprotein convertase. Processing is required for amyloidogenesis, and vesicular trafficking is required for processing (Berson et al. 2003; Hurbain et al. 2008). Furthermore, Pmel17 forms amyloids in the slightly acid ( $\mathrm{pH} \sim 5$ ) environment of the melanosomes, although they dissolve at $\mathrm{pH}>6$ (Watt et al. 2013). In contrast, (pro)vasopressin aggregation in the wrong location (ER vs. secretory granules) causes the neurodegenerative disease diabetes insipidus, showing on the one hand that aggregation per se can be toxic and on the other hand that tight control of functional amyloid aggregation is essential for cell proteostasis (see also above).

In addition, there is often self-regulation of aggregation within the amyloid protein/pep- tide. These include "gatekeeper" residues such as aspartate, glycine, lysine, arginine, or proline that flank aggregation-prone stretches of amino acids and reduce rates or levels of aggregation (and possibly toxicity). A good example is provided by CsgA, whose polymerization is dependent on CsgB-mediated nucleation (Wang et al. 2010). The amyloid core of CsgA features five imperfect repeats (R1-R5) and the three internal repeats were shown to have nonconsensus (gatekeeper) residues. When the gatekeeper residues were mutated to the consensus residues, curli formation in vivo became CsgB-independent, mislocalized, and were associated with cytotoxicity. Analogous gatekeeping roles are played by nonhormone-coding regions in the prohormone, which are often highly hydrophilic or/and charged, effectively constituting a solubility tag; alternatively, they can sequester the aggregation-prone hormone inside the prohormone structure as in the case of provasopressin (Fig. 5A). Also in the case of the HET-S prion, the amino-terminal structured HeLo domain inhibits aggregation and prion infectivity by structural involvement of part of the prion sequence within the HeLo domain (see also above) (Greenwald et al. 2010; Seuring et al. 2012).

\section{Rapid and Focused Aggregation}

There is mounting evidence that a functional amyloid is not just much more stable than a pathological amyloid but also forms more rapidly. The fruit fly Orb2 folds within a few minutes into a functional amyloid, which minimizes the opportunity to accumulate potentially toxic intermediates (Hervás et al. 2016). FapC and CsgA also aggregate on the minute-to-hour scale (depending on concentration) and fibrillation is driven by primary nucleation; secondary processes such as fragmentation and nucleation on the fibril surface are much less pronounced for functional amyloid than for pathological amyloid, no doubt reflecting the role of the folded monomer as the species driving fibrillation (Andreasen et al. 2019). Moreover, no stable oligomeric intermediates of either HET-s, FapC, nor CsgA have been reported. Small mol- 
D. Otzen and R. Riek

A

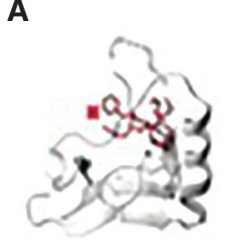

B

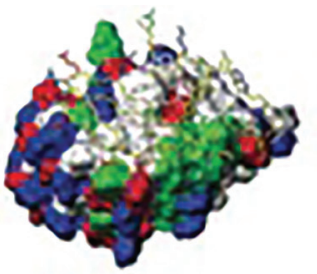

C

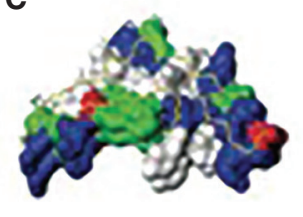

D

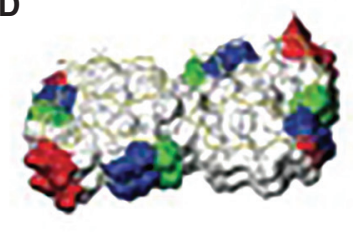

E

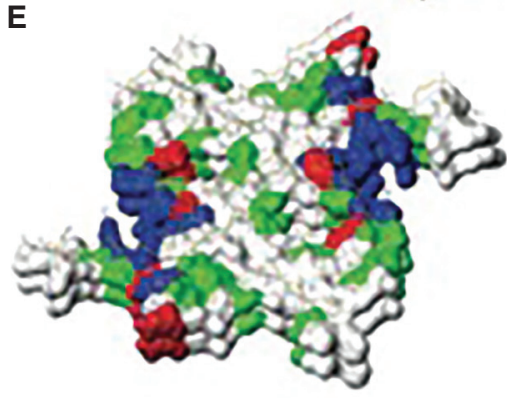

$\mathbf{F}$

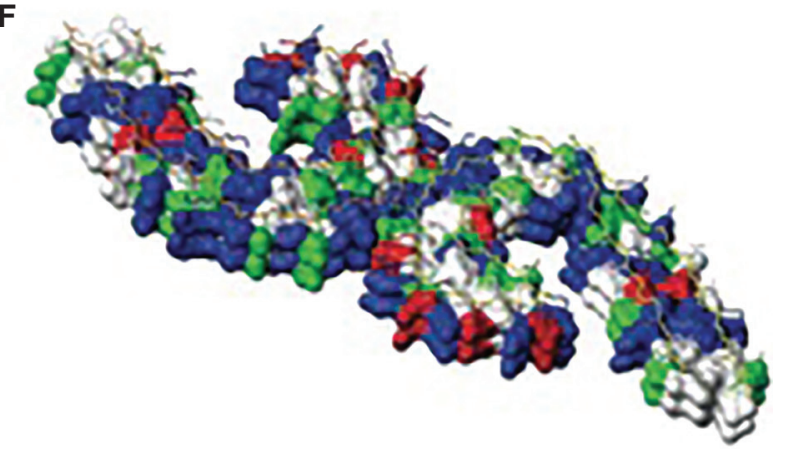

Figure 5. 3D structures of disease versus functional amyloid systems. (A) 3D structure of a fragment of provasopressin comprising vasopressin (represented in red) and neurophysin II (represented by a white ribbon including secondary structural elements; the 1jk4 Protein Data Bank (PDB) (Wu et al. 2001) shows the tight packing of the amyloid-prone vasopressin by neurophysin. Neurophysin II is a segment of provasopressin just carboxy terminal to vasopressin linked by a few amino acid residues indicated by a dashed ribbon. (B) 3D structure of HET-s(218-289) fibrils (Wasmer et al. 2009). (C) 3D structure of $\beta$-endorphin fibrils. (D) 3D structure of $\mathrm{A} \beta(1-42)$ fibrils (Wälti et al. 2016), (E) 3D structure of $\alpha$-synuclein fibrils (Guerrero-Ferreira et al. 2018), (F) 3D structure of tau filaments (Fitzpatrick et al. 2017). Three protein layers for each fibril are shown. The top layer is shown as a bond representation, while for the two lower levels only the surface is shown. The color code for the surfaces and side chains shown are white for hydrophobic, green for polar, red for negatively charged, and blue for positively charged side chains. For HET-s(218-289) fibrils, three molecules per fibril are shown, but each molecule spans two layers. The protonated Glu8 of $\beta$-endorphin fibrils is shown in red, although it is not charged.

ecule inhibitors of aggregation are indeed able to stop aggregation of the latter two proteins at early stages of association, but the resulting species are either monomeric (Andersson et al. 2013) or small oligomers with no cytotoxic properties (Stenvang et al. 2016; Z Najarzadeh and DE Otzen, unpubl.). In summary, it appears that nature has used evolutionary optimization in multiple distinct ways to control formation of amyloid formation with minimal toxicity.

\section{CONCLUSIONS}

Functional amyloids are widespread and show a diverse set of activities ranging from protection and storage to signaling and memory. These functions are related to the multiple properties of the amyloid cross- $\beta$-sheet motif. Both structure and sequence of functional amyloid are evolutionarily optimized for these functions, leading to a well-defined structure-activity relationship. When combined with controlled biophysical conditions in the cell, ancillary proteins and the proteostasis machinery, the mechanism of aggregation is well under control. This contrasts with disease-associated amyloids, in which proteostasis is compromised, the mechanisms of aggregation are rather uncontrolled, and the 3D structures have not been evolutionarily optimized. We remain astounded at the amazing diversity of activity and stability engendered by a single repetitive fold, which can even be formed under prebiotic conditions (Greenwald et al. 2016). 


\section{REFERENCES}

${ }^{*}$ Reference is also in this collection.

Alberti S, Halfmann R, King O, Kapila A, Lindquist S. 2009 A systematic survey identifies prions and illuminates sequence features of prionogenic proteins. Cell 137: 146158. doi:10.1016/j.cell.2009.02.044

Alper T, Cramp WA, Haig DA, Clarke MC. 1967. Does the agent of scrapie replicate without nucleic acid? Nature 214: 764-766. doi:10.1038/214764a0

Alteri CJ, Xicohténcatl-Cortes J, Hess S, Caballero-Olín G, Girón JA, Friedman RL. 2007. Mycobacterium tuberculosis produces pili during human infection. Proc Natl Acad Sci 104: 5145-5150. doi:10.1073/pnas.0602304104

Andersson EK, Bengtsson C, Evans ML, Chorell E, Sellstedt M, Lindgren AEG, Hufnagel DA, Bhattacharya M, Tessier PM, Wittung-Stafshede P, et al. 2013. Modulation of curli assembly and pellicle biofilm formation by chemical and protein chaperones. Chem Biol 20: 1245-1254. doi:10 $.1016 /$ j.chembiol.2013.07.017

Andreasen M, Lorenzen N, Otzen DE. 2015. Interactions between misfolded protein oligomers and membranes: A central topic in neurodegenerative diseases? Biochim Biophys Acta 1848: 1897-1907. doi:10.1016/j.bbamem 2015.01.018

Andreasen M, Meisl G, Taylor JD, Michaels TCT, Levin A, Otzen DE, Chapman MR, Dobson CM, Matthews SJ, Knowles TPJ. 2019. Physical determinants of amyloid assembly in biofilm formation. MBio 10: e02279. doi:10 $.1128 / \mathrm{mBio} .02279-18$

Arvan P, Castle D. 1998. Sorting and storage during secretory granule biogenesis: Looking backward and looking forward. Biochem J 332: 593-610. doi:10.1042/bj3320593

Astbury WT, Dickinson S, Bailey K. 1935. The X-ray interpretation of denaturation and the structure of the seed globulins. Biochem J 29: 2351-2360.1. doi:10.1042/ bj0292351

Balguerie A, Dos Reis S, Ritter C, Chaignepain S, CoularySalin B, Forge V, Bathany K, Lascu I, Schmitter JM, Riek $\mathrm{R}$, et al. 2003. Domain organization and structure-function relationship of the HET-s prion protein of Podospora anserina. EMBO J 22: 2071-2081. doi:10.1093/emboj/ cdg213

Baxa U, Cheng N, Winkler DC, Chiu TK, Davies DR, Sharma D, Inouye H, Kirschner DA, Wickner RB, Steven AC. 2005. Filaments of the Ure2p prion protein have a cross- $\beta$ core structure. J Struct Biol 150: 170-179. doi:10 $.1016 /$ j.jsb.2005.02.007

Berchowitz LE, Walker MR, Kabachinski G, Carlile TM, Gilbert WV, Schwartz TU, Amon A. 2015. Regulated formation of an amyloid-like translational repressor governs gametogenesis. Cell 163: 406-418. doi:10.1016/j.cell.2015 .08 .060

Berson JF, Theos AC, Harper DC, Tenza D, Raposo G, Marks MS. 2003. Proprotein convertase cleavage liberates a fibrillogenic fragment of a resident glycoprotein to initiate melanosome biogenesis. J Cell Biol 161: 521-533. doi:10 $.1083 /$ jcb.200302072

Beuret N, Stettler H, Renold A, Rutishauser J, Spiess M. 2004. Expression of regulated secretory proteins is sufficient to generate granule-like structures in constitutively secreting cells. J Biol Chem 279: 20242-20249. doi:10.1074/jbc .M310613200

Beuret N, Hasler F, Prescianotto-Baschong C, Birk J, Rutishauser J, Spiess M. 2017. Amyloid-like aggregation of provasopressin in diabetes insipidus and secretory granule sorting. BMC Biol 15: 5. doi:10.1186/s12915-0170347-9

Bezsonov EE, Groenning M, Galzitskaya OV, Gorkovskii AA, Semisotnov GV, Selyakh IO, Ziganshin RH, Rekstina VV, Kudryashova IB, Kuznetsov SA, et al. 2013. Amyloidogenic peptides of yeast cell wall glucantransferase $\mathrm{Bgl2} \mathrm{p}$ as a model for the investigation of its $\mathrm{pH}$-dependent fibril formation. Prion 7: 175-184. doi:10.4161/pri .22992

Bian Z, Brauner A, Li Y, Normark S. 2000. Expression of and cytokine activation by Eschevichia coli curli fibers in human sepsis. J Infect Dis 181: 602-612. doi:10.1086/315233

Bieler S, Estrada L, Lagos R, Baeza M, Castilla J, Soto C. 2005. Amyloid formation modulates the biological activity of a bacterial protein. J Biol Chem 280: 26880-26885. doi:10 .1074/jbc.M502031200

Birk J, Friberg MA, Prescianotto-Baschong C, Spiess M, Rutishauser J. 2009. Dominant pro-vasopressin mutants that cause diabetes insipidus form disulfide-linked fibrillar aggregates in the endoplasmic reticulum. J Cell Sci 122: 3994-4002. doi:10.1242/jcs.051136

Blanco LP, Evans ML, Smith DR, Badtke MP, Chapman MR. 2012. Diversity, biogenesis and function of microbial amyloids. Trends Microbiol 20: 66-73. doi:10.1016/j.tim .2011.11.005

Boke E, Ruer M, Wühr M, Coughlin M, Lemaitre R, Gygi SP, Alberti S, Drechsel D, Hyman AA, Mitchison TJ. 2016. Amyloid-like self-assembly of a cellular compartment. Cell 166: 637-650. doi:10.1016/j.cell.2016.06.051

Boyer RR, Sumner SS, Williams RC, Pierson MD, Popham DL, Kniel KE. 2007. Influence of curli expression by Escherichia coli O157:H7 on the cell's overall hydrophobicity, charge, and ability to attach to lettuce. J Food Prot 70: 1339-1345. doi:10.4315/0362-028X-70.6.1339

Bryan JA, Menke M, Cowen LJ, Lindquist SL, Berger B. 2009. BETASCAN: Probable $\beta$-amyloids identified by pairwise probabilistic analysis. PLoS Comput Biol 5: e1000333. doi:10.1371/journal.pcbi.1000333

Caudron F, Barral Y. 2013. A super-assembly of Whi3 encodes memory of deceptive encounters by single cells during yeast courtship. Cell 155: 1244-1257. doi:10 $.1016 /$ j.cell.2013.10.046

Cegelski L, Pinkner JS, Hammer ND, Cusumano CK, Hung CS, Chorell E, Åberg V, Walker JN, Seed PC, Almqvist F, et al. 2009. Small-molecule inhibitors target Escherichia coli amyloid biogenesis and biofilm formation. Nat Chem Biol 5: 913-919. doi:10.1038/nchembio.242

Chai L, Romero D, Kayatekin C, Akabayov B, Vlamakis H, Losick R, Kolter R. 2013. Isolation, characterization, and aggregation of a structured bacterial matrix precursor. $J$ Biol Chem 288: 17559-17568. doi:10.1074/jbc.M113 .453605

Chan CXJ, Lipke PN. 2014. Role of force-sensitive amyloidlike interactions in fungal catch bonding and biofilms. Eukaryotic Cell 13: 1136-1142. doi:10.1128/EC.00068-14

Chan CXJ, El-Kirat-Chatel S, Joseph IG, Jackson DN, Ramsook CB, Dufrêne YF, Lipke PN. 2016. Force sensitivity in 
D. Otzen and R. Riek

Saccharomyces cerevisiae flocculins. mSphere 1: e0012816. doi:10.1128/mSphere.00128-16

Chapman MR, Robinson LS, Pinkner JS, Roth R, Heuser J, Hammar M, Normark S, Hultgren SJ. 2002. Role of Escherichia coli curli operons in directing amyloid fiber formation. Science 295: 851-855. doi:10.1126/science .1067484

Chiti F, Dobson CM. 2006. Protein misfolding, functional amyloid, and human disease. Annu Rev Biochem 75: 333 366. doi:10.1146/annurev.biochem.75.101304.123901

Christensen LFB, Schafer N, Wolf-Perez AM, Madsen DJ, Otzen DE. 2019. Bacterial amyloids: Biogenesis and biomaterials. In Biological and bio-inspired nanomaterials: Assembly mechanisms and properties (ed. Perrett S, Buell A, Knowles T). Springer, New York.

Claessen D, Rink R, de Jong W, Siebring J, de Vreugd P, Boersma FGH, Dijkhuizen L, Wosten HAB. 2003. A nove class of secreted hydrophobic proteins is involved in aerial hyphae formation in Streptomyces coelicolor by forming amyloid-like fibrils. Genes Dev 17: 1714-1726. doi:10 $.1101 /$ gad. 264303

Collinson SK, Emödy L, Müller KH, Trust TJ, Kay WW. 1991. Purification and characterization of thin, aggregative fimbriae from Salmonella enteritidis. J Bacteriol 173: 4773-4781. doi:10.1128/jb.173.15.4773-4781.1991

Colvin MT, Silvers R, Ni QZ, Can TV, Sergeyev I, Rosay M, Donovan KJ, Michael B, Wall J, Linse S, et al. 2016. Atomic resolution structure of monomorphic $A \beta 42$ amyloid fibrils. J Am Chem Soc 138: 9663-9674. doi:10.1021/jacs .6b05129

Conchillo-Solé O, de Groot NS, Avilés FX, Vendrell J, Daura X, Ventura S. 2007. AGGRESCAN: A server for the prediction and evaluation of "hot spots" of aggregation in polypeptides. BMC Bioinformatics 8: 65. doi:10.1186/ 1471-2105-8-65

Coustou V, Deleu C, Saupe S, Begueret J. 1997. The protein product of the het-s heterokaryon incompatibility gene of the fungus Podospora anserina behaves as a prion analog. Proc Natl Acad Sci 94: 9773-9778. doi:10.1073/pnas.94 18.9773

Danielsen HN, Hansen SH, Herbst FA, Kjeldal H, Stensballe A, Nielsen PH, Dueholm MS. 2017. Direct identification of functional amyloid proteins by label-free quantitative mass spectrometry. Biomolecules 7: 58. doi:10.3390/biom 7030058

Dannies PS. 2001. Concentrating hormones into secretory granules: Layers of control. Mol Cell Endocrinol 177: 87 93. doi:10.1016/S0303-7207(01)00437-3

Daskalov A, Paoletti M, Ness F, Saupe SJ. 2012. Genomic clustering and homology between HET-S and the NWD2 STAND protein in various fungal genomes. PLOS ONE 7: e34854. doi:10.1371/journal.pone.0034854

Daskalov A, Gantner M, Wälti MA, Schmidlin T, Chi CN, Wasmer C, Schütz A, Ceschin J, Clavé C, Cescau S, et al. 2014. Contribution of specific residues of the $\beta$-solenoid fold to HET-s prion function, amyloid structure and stability. PLoS Pathog 10: e1004158. doi:10.1371/journal .ppat.1004158

Derkatch IL, Bradley ME, Masse SVL, Zadorsky SP, Polozkov GV, Inge-Vechtomov SG, Liebman SW. 2000. Dependence and independence of $\left[\mathrm{PSI}^{+}\right]$and $\left[\mathrm{PIN}^{+}\right]$: A two- prion system in yeast? EMBO J 19: 1942-1952. doi:10 $.1093 / \mathrm{emboj} / 19.9 .1942$

Destoumieux-Garzón D, Thomas X, Santamaria M, Goulard C, Barthélémy M, Boscher B, Bessin Y, Molle G, Pons AM, Letellier L, et al. 2003. Microcin E492 antibacterial activity: Evidence for a TonB-dependent inner membrane permeabilization on Escherichia coli. Mol Microbiol 49: 1031-1041. doi:10.1046/j.1365-2958.2003.03610.x

Du Z, Park KW, Yu H, Fan Q, Li L. 2008. Newly identified prion linked to the chromatin-remodeling factor Swil in Saccharomyces cerevisiae. Nat Genet 40: 460-465. doi:10 $.1038 /$ ng.112

Dueholm MS, Petersen SV, Sønderkær M, Larsen P, Christiansen G, Hein KL, Enghild JJ, Nielsen JL, Nielsen KL, Nielsen PH, et al. 2010. Functional amyloid in Pseudomonas. Mol Microbiol 77: 1009-1020.

Dueholm MS, Nielsen SB, Hein KL, Nissen P, Chapman M, Christiansen G, Nielsen PH, Otzen DE. 2011. Fibrillation of the major curli subunit CsgA under a wide range of conditions implies a robust design of aggregation. Biochemistry 50: 8281-8290. doi:10.1021/bi200967c

Dueholm MS, Albertsen M, Otzen D, Nielsen PH. 2012. Curli functional amyloid systems are phylogenetically widespread and display large diversity in operon and protein structure. PLoS ONE 7: e51274. doi:10.1371/journal .pone. 0051274

Dueholm MS, Otzen DE, Nielsen PH. 2013a. Evolutionary insight into the functional amyloids of the Pseudomonads. PLoS ONE 8: e76630. doi:10.1371/journal.pone .0076630

Dueholm MS, Søndergaard MT, Nilsson M, Christiansen G, Stensballe A, Overgaard MT, Givskov M, Tolker-Nielsen T, Otzen DE, Nielsen PH. 2013b. Expression of Fap amyloids in Pseudomonas aeruginosa, P. fluorescens, and $P$. putida results in aggregation and increased biofilm formation. Microbiologyopen 2: 365-382. doi:10.1002/ mbo3.81

Dueholm MS, Larsen P, Finster K, Stenvang MR, Christiansen G, Vad BS, Bøggild A, Otzen DE, Nielsen PH. 2015. The tubular sheaths encasing Methanosaeta thermophila filaments are functional amyloids. J Biol Chem 290: 20590-20600. doi:10.1074/jbc.M115.654780

Eisenberg DS, Sawaya MR. 2017. Structural studies of amyloid proteins at the molecular level. Annu Rev Biochem $\mathbf{8 6}$ 69-95. doi:10.1146/annurev-biochem-061516-045104

Evans ML, Chorell E, Taylor JD, Åden J, Götheson A, Li F, Koch M, Sefer L, Matthews SJ, Wittung-Stafshede P, et al 2015. The bacterial curli system possesses a potent and selective inhibitor of amyloid formation. Mol Cell 57: 445-455. doi:10.1016/j.molcel.2014.12.025

Fernandez-Escamilla A-M, Rousseau F, Schymkowitz J, Serrano L. 2004. Prediction of sequence-dependent and mutational effects on the aggregation of peptides and proteins. Nat Biotechnol 22: 1302-1306. doi:10.1038/ nbt1012

Fitzpatrick AWP, Falcon B, He S, Murzin AG, Murshudov G, Garringer HJ, Crowther RA, Ghetti B, Goedert M, Scheres SHW. 2017. Cryo-EM structures of tau filaments from Alzheimer's disease. Nature 547: 185-190. doi:10.1038/ nature 23002

Fowler DM, Koulov AV, Alory-Jost C, Marks MS, Balch WE, Kelly JW. 2006. Functional amyloid formation within 
mammalian tissue. PLoS Biol 4: e6. doi:10.1371/journal .pbio.0040006

Garbuzynskiy SO, Lobanov MY, Galzitskaya OV. 2010 FoldAmyloid: A method of prediction of amyloidogenic regions from protein sequence. Bioinformatics 26: 326332. doi:10.1093/bioinformatics/btp691

Gazit E. 2002. A possible role for $\pi$-stacking in the self-assembly of amyloid fibrils. FASEB J 16: 77-83. doi:10 .1096/fj.01-0442hyp

Gebbink MFBG, Claessen D, Bouma B, Dijkhuizen L, Wösten HAB. 2005. Amyloids-A functional coat for microorganisms. Nat Rev Microbiol 3: 333-341. doi:10.1038/ nrmicro1127

Gellermann GP, Appel TR, Tannert A, Radestock A, Hortschansky P, Schroeckh V, Leisner C, Lütkepohl T, Shtrasburg S, Röcken C, et al. 2005. Raft lipids as common components of human extracellular amyloid fibrils. Proc Natl Acad Sci 102: 6297-6302. doi:10.1073/pnas.040 7035102

Giasson BI, Forman MS, Higuchi M, Golbe LI, Graves CL, Kotzbauer PT, Trojanowski JQ, Lee VM-Y. 2003. Initiation and synergistic fibrillization of tau and $\alpha$-synuclein Science 300: 636-640. doi:10.1126/science.1082324

Giehm L, Otzen DE. 2013. Experimental approaches to inducing amyloid aggregates. In Amyloid fibrils and prefibrillar aggregates (ed. Otzen DE), pp. 295-320. Wiley, Hoboken, NJ.

Glass NL, Dementhon K. 2006. Non-self recognition and programmed cell death in filamentous fungi. Curr Opin Microbiol 9: 553-558. doi:10.1016/j.mib.2006.09.001

Gophna U, Barlev M, Seijffers R, Oelschlager TA, Hacker J, Ron EZ. 2001. Curli fibers mediate internalization of Escherichia coli by eukaryotic cells. Infect Immun 69: 26592665. doi:10.1128/IAI.69.4.2659-2665.2001

Gößler-Schöfberger R, Hesser G, Muik M, Wechselberger C, Jilek A. 2009. An orphan dermaseptin from frog skin reversibly assembles to amyloid-like aggregates in a $\mathrm{pH}$ dependent fashion. FEBS J 276: 5849-5859. doi:10.1111/j 1742-4658.2009.07266.x

Goyal P, Krasteva PV, Van Gerven N, Gubellini F, Van den Broeck I, Troupiotis-Tsailaki A, Jonckheere W, PéhauArnaudet G, Pinkner JS, Chapman MR, et al. 2014. Structural and mechanistic insights into the bacterial amyloid secretion channel CsgG. Nature 516: 250-253. doi:10 .1038 /nature 13768

Green JR, Buchan GC, Alvord EC, Swanson AG. 1967. Hereditary and idiopathic types of diabetes insipidus. Brain 90: 707-714. doi:10.1093/brain/90.3.707

Greenwald J, Riek R. 2010. Biology of amyloid: Structure, function, and regulation. Structure 18: 1244-1260. doi:10 $.1016 /$ j.str.2010.08.009

Greenwald J, Buhtz C, Ritter C, Kwiatkowski W, Choe S, Maddelein ML, Ness F, Cescau S, Soragni A, Leitz D, et al. 2010. The mechanism of prion inhibition by HET-S. Mol Cell 38: 889-899. doi:10.1016/j.molcel.2010.05.019

Greenwald J, Friedmann MP, Riek R. 2016. Amyloid aggregates arise from amino acid condensations under prebiotic conditions. Angew Chem Int Ed Engl 55: 1160911613. doi:10.1002/anie.201605321
Greenwald J, Kwiatkowski W, Riek R. 2018. Peptide amyloids in the origin of life. J Mol Biol 430: 3735-3750. doi:10.1016/j.jmb.2018.05.046

Guerrero-Ferreira R, Taylor NM, Mona D, Ringler P, Lauer ME, Riek R, Britschgi M, Stahlberg H. 2018. Cryo-EM structure of $\alpha$-synuclein fibrils. eLife 7: e36402. doi:10 $.7554 /$ eLife.36402

Guyonnet B, Egge N, Cornwall GA. 2014. Functional amyloids in the mouse sperm acrosome. Mol Cell Biol 34: 2624-2634. doi:10.1128/MCB.00073-14

Hammar M, Arnqvist A, Bian Z, Olsén A, Normark S. 1995. Expression of two csg operons is required for production of fibronectin- and congo red-binding curli polymers in Escherichia coli K-12. Mol Microbiol 18: 661-670. doi:10 .1111/j.1365-2958.1995.mmi_18040661.x

Hammar M, Bian Z, Normark S. 1996. Nucleator-dependent intercellular assembly of adhesive curli organelles in $E s$ cherichia coli. Proc Natl Acad Sci 93: 6562-6566. doi:10 $.1073 /$ pnas.93.13.6562

Hammer ND, Schmidt JC, Chapman MR. 2007. The curli nucleator protein, $\mathrm{CsgB}$, contains an amyloidogenic domain that directs CsgA polymerization. Proc Natl Acad Sci 104: 12494-12499. doi:10.1073/pnas.0703310104

Han H, Weinreb PH, Lansbury PT. 1995. The core Alzheimer's peptide NAC forms amyloid fibrils which seed and are seeded by $\beta$-amyloid: Is NAC a common trigger or target in neurodegenerative disease? Chem Biol 2: 163 169. doi:10.1016/1074-5521(95)90071-3

Herczenik E, Bouma B, Korporaal SJA, Strangi R, Zeng Q, Gros P, Eck MV, Berkel TJCV, Gebbink MFBG, Akkerman JWN. 2007. Activation of human platelets by misfolded proteins. Arterioscler Thromb Vasc Biol 27: 16571665. doi:10.1161/ATVBAHA.107.143479

Hervás R, Li L, Majumdar A, Fernández-Ramírez MdC, Unruh JR, Slaughter BD, Galera-Prat A, Santana E, Suzuki M, Nagai Y, et al. 2016. Molecular basis of Orb2 amyloidogenesis and blockade of memory consolidation. PLoS Biol 14: e1002361. doi:10.1371/journal.pbio.100 2361

Hewetson A, Do HQ, Myers C, Muthusubramanian A, Sutton RB, Wylie BJ, Cornwall GA. 2017. Functional amyloids in reproduction. Biomolecules 7: 46. doi:10.3390/ biom7030046

Hurbain I, Geerts WJC, Boudier T, Marco S, Verkleij AJ, Marks MS, Raposo G. 2008. Electron tomography of early melanosomes: Implications for melanogenesis and the generation of fibrillar amyloid sheets. Proc Natl Acad Sci 105: 19726-19731. doi:10.1073/pnas.0803488105

Iconomidou VA, Vriend G, Hamodrakas SJ. 2000. Amyloids protect the silkmoth oocyte and embryo. FEBS Lett 479: 141-145. doi:10.1016/S0014-5793(00)01888-3

Ishihama A. 2010. Prokaryotic genome regulation: multifactor promoters, multitarget regulators and hierarchic networks. FEMS Microbiol Rev 34: 628-645. doi:10.1111/j .1574-6976.2010.00227.x

* Jayaraj GG, Hipp MS, Hartl FU. 2019. Functional modules of the proteostasis network. Cold Spring Harb Perspect Biol doi:10.1101/cshperspect.a033951

Jordal PB, Dueholm MS, Larsen P, Petersen SV, Enghild JJ, Christiansen G, Højrup P, Nielsen PH, Otzen DE. 2009. Widespread abundance of functional bacterial amyloid in 
D. Otzen and R. Riek

mycolata and other gram-positive bacteria. Appl Environ Microbiol 75: 4101-4110. doi:10.1128/AEM.02107-08

Kaganovich D, Kopito R, Frydman J. 2008. Misfolded proteins partition between two distinct quality control compartments. Nature 454: 1088-1095. doi:10.1038/nat ure07195

Kai-Larsen Y, Lüthje P, Chromek M, Peters V, Wang X, Holm Å, Kádas L, Hedlund KO, Johansson J, Chapman MR, et al. 2010. Uropathogenic Escherichia coli modulates immune responses and its curli fimbriae interact with the antimicrobial peptide LL-37. PLoS Pathog 6: e1001010. doi:10.1371/journal.ppat.1001010

Kelly RB. 1985. Pathways of protein secretion in eukaryotes. Science 230: 25-32. doi:10.1126/science.2994224

Kelly RB. 1987. Protein transport. From organelle to organelle. Nature 326: 14-15. doi:10.1038/326014a0

Kleino A, Ramia NF, Bozkurt G, Shen Y, Nailwal H, Huang J, Napetschnig J, Gangloff M, Chan FK-M, Wu H, et al 2017. Peptidoglycan-sensing receptors trigger the formation of functional amyloids of the adaptor protein Imd to initiate Drosophila NF- $\mathrm{\kappa B}$ signaling. Immunity 47: 635647.e6. doi:10.1016/j.immuni.2017.09.011

Kranenburg O, Bouma B, Kroon-Batenburg LMJ, Reijerkerk A, Wu YP, Voest EE, Gebbink MFBG. 2002. Tissue-type plasminogen activator is a multiligand cross- $\beta$ structure receptor. Curr Biol 12: 1833-1839. doi:10.1016/S09609822(02)01224-1

Larsen P, Nielsen JL, Dueholm MS, Wetzel R, Otzen DE, Nielsen PH. 2007. Amyloid adhesins are abundant in natural biofilms. Environ Microbiol 9: 3077-3090. doi:10.1111/j.1462-2920.2007.01418.x

Lembré P, Vendrely C, Martino PD. 2014. Identification of an amyloidogenic peptide from the Bap protein of Staphylococcus epidermidis. Protein Pept Lett 21: 75-79. doi:10 $.2174 / 09298665113209990072$

Li J, McQuade T, Siemer AB, Napetschnig J, Moriwaki K, Hsiao YS, Damko E, Moquin D, Walz T, McDermott A, et al. 2012. The RIP1/RIP3 necrosome forms a functional amyloid signaling complex required for programmed necrosis. Cell 150: 339-350. doi:10.1016/j.cell.2012.06.019

Macindoe I, Kwan AH, Ren Q, Morris VK, Yang W, Mackay JP, Sunde M. 2012. Self-assembly of functional, amphipathic amyloid monolayers by the fungal hydrophobin EAS. Proc Natl Acad Sci 109: E804-E811. doi:10.1073/ pnas.1114052109

Maddelein M-L, Dos Reis S, Duvezin-Caubet S, CoularySalin B, Saupe SJ. 2002. Amyloid aggregates of the HET-s prion protein are infectious. Proc Natl Acad Sci 99: 7402-7407. doi:10.1073/pnas.072199199

Maji SK, Perrin MH, Sawaya MR, Jessberger S, Vadodaria K, Rissman RA, Singru PS, Nilsson KPR, Simon R, Schubert D, et al. 2009a. Functional amyloids as natural storage of peptide hormones in pituitary secretory granules. Science 325: 328-332. doi:10.1126/science.1173155

Maji S, Wang L, Greenwald J, Riek R. 2009b. Structureactivity relationship of amyloid fibrils. FEBS Lett 583: 2610-2617. doi:10.1016/j.febslet.2009.07.003

Manara A, DalCorso G, Baliardini C, Farinati S, Cecconi D, Furini A. 2012. Pseudomonas putida response to cadmium: Changes in membrane and cytosolic proteomes. J Proteome Res 11: 4169-4179. doi:10.1021/pr300281f
Markande AR, Nerurkar AS. 2016. Bioemulsifier (BE-AM1) produced by Solibacillus silvestris AM1 is a functional amyloid that modulates bacterial cell-surface properties. Biofouling 32: 1153-1162. doi:10.1080/08927014.2016 .1232716

Mathur V, Seuring C, Riek R, Saupe SJ, Liebman SW. 2012 Localization of HET-S to the cell periphery, not to [Het-s] aggregates, is associated with [Het-s]-HET-S toxicity. Mol Cell Biol 32: 139-153. doi:10.1128/MCB.06125-11

Maurer-Stroh S, Debulpaep M, Kuemmerer N, Paz Mdl, Martins IC, Reumers J, Morris KL, Copland A, Serpell L, Serrano L, et al. 2010. Exploring the sequence determinants of amyloid structure using position-specific scoring matrices. Nat Methods 7: 237-242. doi:10.1038/nmeth .1432

Morris VK, Kwan AH, Sunde M. 2013. Analysis of the structure and conformational states of DewA gives insight into the assembly of the fungal hydrophobins. J Mol Biol 425: 244-256. doi:10.1016/j.jmb.2012.10.021

Nelson R, Sawaya MR, Balbirnie M, Madsen AØ, Riekel C, Grothe R, Eisenberg D. 2005. Structure of the cross- $\beta$ spine of amyloid-like fibrils. Nature 435: 773-778. doi:10.1038/nature 03680

Nenninger AA, Robinson LS, Hammer ND, Epstein EA, Badtke MP, Hultgren SJ, Chapman MR. 2011. CsgE is a curli secretion specificity factor that prevents amyloid fibre aggregation. Mol Microbiol 81: 486-499. doi:10 $.1111 / \mathrm{j} .1365-2958.2011 .07706 . \mathrm{x}$

Nespovitaya N, Gath J, Barylyuk K, Seuring C, Meier BH, Riek R. 2016. Dynamic assembly and disassembly of functional $\beta$-endorphin amyloid fibrils. J Am Chem Soc 138: 846-856. doi:10.1021/jacs.5b08694

Nguyen PQ, Botyanszki Z, Tay PKR, Joshi NS. 2014. Programmable biofilm-based materials from engineered curli nanofibres. Nat Commun 5: 4945. doi:10.1038/ ncomms5945

Oh J, Kim JG, Jeon E, Yoo CH, Moon JS, Rhee S, Hwang I. 2007. Amyloidogenesis of type III-dependent harpins from plant pathogenic bacteria. J Biol Chem 282: 13601-13609. doi:10.1074/jbc.M602576200

Oli MW, Otoo HN, Crowley PJ, Heim KP, Nascimento MM, Ramsook CB, Lipke PN, Brady LJ. 2012. Functional amyloid formation by Streptococcus mutants. Microbiology 158: 2903-2916. doi:10.1099/mic.0.060855-0

Olsén A, Jonsson A, Normark S. 1989. Fibronectin binding mediated by a novel class of surface organelles on Escherichia coli. Nature 338: 652-655. doi:10.1038/338652a0

Olsén A, Wick MJ, Mörgelin M, Björck L. 1998. Curli, fibrous surface proteins of Escherichia coli, interact with major histocompatibility complex class I molecules. Infect Immun 66: 944-949.

Pawar DM, Rossman ML, Chen J. 2005. Role of curli fimbriae in mediating the cells of enterohaemorrhagic Escherichia coli to attach to abiotic surfaces. J Appl Microbiol 99: 418-425. doi:10.1111/j.1365-2672.2005.02499.x

Pearson JS, Giogha C, Mühlen S, Nachbur U, Pham CLL, Zhang Y, Hildebrand JM, Oates CV, Lung TWF, Ingle D, et al. 2017. EspL is a bacterial cysteine protease effector that cleaves RHIM proteins to block necroptosis and inflammation. Nat Microbiol 2: 16258. doi:10.1038/nmi crobiol.2016.258 
Pedersen JS, Andersen CB, Otzen DE. 2010. Amyloid structure-One but not the same: The many levels of fibrillar polymorphism. FEBS J 277: 4591-4601. doi:10.1111/j .1742-4658.2010.07888.x

Peelaerts W, Bousset L, Van der Perren A, Moskalyuk A, Pulizzi R, Giugliano M, Van den Haute C, Melki R, Baekelandt V. 2015. $\alpha$-Synuclein strains cause distinct synucleinopathies after local and systemic administration. Nature 522: 340-344. doi:10.1038/nature14547

Petersen TN, Brunak S, von Heijne G, Nielsen H. 2011. SignalP 4.0: Discriminating signal peptides from transmembrane regions. Nat Methods 8: 785-786. doi:10 $.1038 /$ nmeth.1701

Petkova AT, Leapman RD, Guo Z, Yau WM, Mattson MP, Tycko R. 2005. Self-propagating, molecular-level polymorphism in Alzheimer's $\beta$-amyloid fibrils. Science 307: 262-265. doi:10.1126/science.1105850

Pezza JA, Villali J, Sindi SS, Serio TR. 2014. Amyloid-associated activity contributes to the severity and toxicity of a prion phenotype. Nat Commun 5: 4384. doi:10.1038/ ncomms5384

Pham CL, Shanmugam N, Strange M, O'Carroll A, Brown JW, Sierecki E, Gambin Y, Steain M, Sunde M. 2019. Viral M45 and necroptosis-associated proteins form heteromeric amyloid assemblies. EMBO Rep 20: e46518. doi:10.15252/embr.201846518

Pinan-Lucarré B, Paoletti M, Clavé C. 2007. Cell death by incompatibility in the fungus Podospora. Semin Cancer Biol 17: 101-111. doi:10.1016/j.semcancer.2006.11.009

Podrabsky JE, Carpenter JF, Hand SC. 2001. Survival of water stress in annual fish embryos: Dehydration avoidance and egg envelope amyloid fibers. Am J Physiol Regul Integr Comp Physiol 280: R123-R131. doi:10.1152/aj pregu.2001.280.1.R123

Prusiner SB. 1998. Prions. Proc Natl Acad Sci 95: 13363 13383. doi:10.1073/pnas.95.23.13363

Rasmussen CB, Christiansen G, Vad BS, Lynggaard C, Enghild JJ, Andreasen M, Otzen D. 2019. Imperfect repeats in the functional amyloid protein FapC reduce the tendency to fragment during fibrillation. Protein Sci 28: 633642. doi:10.1002/pro.3566

Reynolds NP, Soragni A, Rabe M, Verdes D, Liverani E, Handschin S, Riek R, Seeger S. 2011. Mechanism of membrane interaction and disruption by $\alpha$-synuclein. $J \mathrm{Am}$ Chem Soc 133: 19366-19375. doi:10.1021/ja2029848

Riek R, Eisenberg DS. 2016. The activities of amyloids from a structural perspective. Nature 539: 227-235. doi:10.1038/ nature20416

Riek R, Saupe SJ. 2016. The HET-S/s prion motif in the control of programmed cell death. Cold Spring Harb Perspect Biol 8: a023515. doi:10.1101/cshperspect.a023515

Ritter C, Maddelein ML, Siemer AB, Lührs T, Ernst M, Meier BH, Saupe SJ, Riek R. 2005. Correlation of structural elements and infectivity of the HET-s prion. Nature 435: 844-848. doi:10.1038/nature03793

Romero D, Aguilar C, Losick R, Kolter R. 2010. Amyloid fibers provide structural integrity to Bacillus subtilis biofilms. Proc Natl Acad Sci 107: 2230-2234. doi:10.1073/ pnas.0910560107

Rouse SL, Hawthorne WJ, Berry JL, Chorev DS, Ionescu SA, Lambert S, Stylianou F, Ewert W, Mackie U, Morgan
RML, et al. 2017. A new class of hybrid secretion system is employed in Pseudomonas amyloid biogenesis. Nat Commun 8: 263. doi:10.1038/s41467-017-00361-6

Rouse SL, Matthews SJ, Dueholm MS. 2018. Ecology and biogenesis of functional amyloids in Pseudomonas. J Mol Biol 430: 3685-3695. doi:10.1016/j.jmb.2018.05.004

Saad S, Cereghetti G, Feng Y, Picotti P, Peter M, Dechant R. 2017. Reversible protein aggregation is a protective mechanism to ensure cell cycle restart after stress. Nat Cell Biol 19: 1202-1213. doi:10.1038/ncb3600

Saarikangas J, Barral Y. 2016. Protein aggregation as a mechanism of adaptive cellular responses. Curr Genet 62: 711724. doi:10.1007/s00294-016-0596-0

Sawaya MR, Sambashivan S, Nelson R, Ivanova MI, Sievers SA, Apostol MI, Thompson MJ, Balbirnie M, Wiltzius JJW, McFarlane HT, et al. 2007. Atomic structures of amyloid cross $-\beta$ spines reveal varied steric zippers. Nature 447: 453-457. doi:10.1038/nature05695

Schwartz K, Syed AK, Stephenson RE, Rickard AH, Boles BR. 2012. Functional amyloids composed of phenol soluble modulins stabilize Staphylococcus aureus biofilms. PLoS Pathog 8: e1002744. doi:10.1371/journal.ppat.100 2744

Seuring C, Greenwald J, Wasmer C, Wepf R, Saupe SJ, Meier BH, Riek R. 2012. The mechanism of toxicity in HET-S/ HET-s prion incompatibility. PLoS Biol 10: e1001451. doi:10.1371/journal.pbio.1001451

Seuring C, Nespovitaya N, Rutishauser J, Spiess M, Riek R. 2013. Hormone amyloids in sickness and in health. In Amyloid fibrils and prefibrillar aggregates (ed. Otzen DE), pp. 395-410. Wiley, Hoboken, NJ. doi:10.1002/ 9783527654185.ch18

Seviour T, Hansen SH, Yang L, Yau YH, Wang VB, Stenvang MR, Christiansen G, Marsili E, Givskov M, Chen Y, et al. 2015. Functional amyloids keep quorum-sensing molecules in check. J Biol Chem 290: 6457-6469. doi:10.1074/ jbc.M114.613810

Shewmaker F, McGlinchey RP, Thurber KR, McPhie P, Dyda F, Tycko R, Wickner RB. 2009. The functional curli amyloid is not based on in-register parallel $\beta$-sheet structure. J Biol Chem 284: 25065-25076. doi:10.1074/jbc.M109 .007054

Shorter J, Lindquist S. 2005. Prions as adaptive conduits of memory and inheritance. Nat Rev Genet 6: 435-450. doi: $10.1038 / \operatorname{nrg} 1616$

Sivanathan V, Hochschild A. 2013. A bacterial export system for generating extracellular amyloid aggregates. Nat Protoc 8: 1381-1390. doi:10.1038/nprot.2013.081

Soragni A, Yousefi S, Stoeckle C, Soriaga AB, Sawaya MR, Kozlowski E, Schmid I, Radonjic-Hoesli S, Boutet S, Williams GJ, et al. 2015. Toxicity of eosinophil MBP is repressed by intracellular crystallization and promoted by extracellular aggregation. Mol Cell 57: 1011-1021. doi:10 .1016/j.molcel.2015.01.026

Sparr E, Engel MFM, Sakharov DV, Sprong M, Jacobs J, de Kruijff B, Höppener JWM, Killian JA. 2004. Islet amyloid polypeptide-induced membrane leakage involves uptake of lipids by forming amyloid fibers. FEBS Lett 577: 117120. doi:10.1016/j.febslet.2004.09.075

Stenvang M, Dueholm MS, Vad BS, Seviour T, Zeng G, Geifman-Shochat S, Søndergaard MT, Christiansen G, Meyer RL, Kjelleberg S, et al. 2016. Epigallocatechin gallate 
D. Otzen and R. Riek

remodels overexpressed functional amyloids in Pseudomonas aeruginosa and increases biofilm susceptibility to antibiotic treatment. J Biol Chem 291: 26540-26553. doi:10.1074/jbc.M116.739953

Sunde M, Blake C. 1997. The structure of amyloid fibrils by electron microscopy and X-ray diffraction. Adv Protein Chem 50: 123-159. doi:10.1016/S0065-3233(08)60320-4

Taglialegna A, Navarro S, Ventura S, Garnett JA, Matthews S, Penades JR, Lasa I, Valle J. 2016. Staphylococcal Bap proteins build amyloid scaffold biofilm matrices in response to environmental signals. PLoS Pathog 12: e1005711. doi:10.1371/journal.ppat.1005711

Taneja V, Maddelein ML, Talarek N, Saupe SJ, Liebman SW. 2007. A non-Q/N-rich prion domain of a foreign prion, [Het-s], can propagate as a prion in yeast. Mol Cell 27: 6777. doi:10.1016/j.molcel.2007.05.027

Taylor JD, Hawthorne WJ, Lo J, Dear A, Jain N, Meisl G Andreasen M, Fletcher C, Koch M, Darvill N, et al. 2016. Electrostatically-guided inhibition of curli amyloid nucleation by the CsgC-like family of chaperones. Sci Rep 6: 24656. doi:10.1038/srep24656

Tian P, Boomsma W, Wang Y, Otzen DE, Jensen MH, Lindorff-Larsen K. 2015. Structure of a functional amyloid protein subunit computed using sequence variation. J Am Chem Soc 137: 22-25. doi:10.1021/ja5093634

True HL, Lindquist SL. 2000. A yeast prion provides a mechanism for genetic variation and phenotypic diversity. $\mathrm{Na}$ ture 407: 477-483. doi:10.1038/35035005

Turcq B, Deleu C, Denayrolles M, Bégueret J. 1991. Two allelic genes responsible for vegetative incompatibility in the fungus Podospora anserina are not essential for cell viability. Mol Gen Genet 228: 265-269. doi:10.1007/ BF00282475

Verasdonck J. 2017. "The solid state NMR observations on ammyloid fibrils." PhD thesis doi:10.3929/ethz-b000161480

Walsh I, Seno F, Tosatto SCE, Trovato A. 2014. PASTA 2.0: An improved server for protein aggregation prediction. Nucleic Acids Res 42: W301-W307. doi:10.1093/nar/ gku399

Wälti MA, Ravotti F, Arai H, Glabe CG, Wall JS, Böckmann A, Güntert P, Meier BH, Riek R. 2016. Atomic-resolution structure of a disease-relevant $A \beta(1-42)$ amyloid fibril. Proc Natl Acad Sci 113: E4976-E4984. doi:10.1073/pnas .1600749113

Wang X, Chapman MR. 2008. Sequence determinants of bacterial amyloid formation. J Mol Biol 380: 570-580. doi:10.1016/j.jmb.2008.05.019

Wang L, Maji SK, Sawaya MR, Eisenberg D, Riek R. 2008. Bacterial inclusion bodies contain amyloid-like structure. PLoS Biol 6: e195. doi:10.1371/journal.pbio.0060195

Wang X, Zhou Y, Ren JJ, Hammer ND, Chapman MR. 2010. Gatekeeper residues in the major curlin subunit modulate bacterial amyloid fiber biogenesis. Proc Natl Acad Sci 107: 163-168. doi:10.1073/pnas.0908714107

Wasmer C, Soragni A, Sabaté R, Lange A, Riek R, Meier BH. 2008. Infectious and noninfectious amyloids of the HET-s(218-289) prion have different NMR spectra. Angew Chem Int Ed Engl 47: 5839-5841. doi:10.1002/anie .200704896
Wasmer C, Schütz A, Loquet A, Buhtz C, Greenwald J, Riek R, Böckmann A, Meier BH. 2009. The molecular organization of the fungal prion HET-s in its amyloid form. $J$ Mol Biol 394: 119-127. doi:10.1016/j.jmb.2009.09.015

Watt B, van Niel G, Raposo G, Marks MS. 2013. PMEL: A pigment cell-specific model for functional amyloid formation. Pigment Cell Melanoma Res 26: 300-315. doi:10 $.1111 / \mathrm{pcmr} .12067$

Westermark P, Grimelius L, Polak JM, Larsson LI, Van Noorden S, Wilander E, Pearse AG. 1977. Amyloid in polypeptide hormone-producing tumors. Lab Invest 37 : 212-215.

Whelly S, Johnson S, Powell J, Borchardt C, Hastert MC, Cornwall GA. 2012. Nonpathological extracellular amyloid is present during normal epididymal sperm maturation. PLoS ONE 7: e36394. doi:10.1371/journal.pone .0036394

Whelly S, Muthusubramanian A, Powell J, Johnson S, Hastert MC, Cornwall GA. 2016. Cystatin-related epididymal spermatogenic subgroup members are part of an amyloid matrix and associated with extracellular vesicles in the mouse epididymal lumen. Mol Hum Reprod 22: 729744. doi:10.1093/molehr/gaw049

Wickner RB. 2016. Yeast and fungal prions. Cold Spring Harb Perspect Biol 8: a023531. doi:10.1101/cshperspect .a023531

Wolynes PG. 2015. Evolution, energy landscapes and the paradoxes of protein folding. Biochimie 119: 218-230. doi:10.1016/j.biochi.2014.12.007

Wösten HA, de Vocht ML. 2000. Hydrophobins, the fungal coat unravelled. Biochim Biophys Acta 1469: 79-86. doi:10.1016/S0304-4157(00)00002-2

Wu CK, Hu B, Rose JP, Liu ZJ, Nguyen TL, Zheng C, Breslow E, Wang BC. 2001. Structures of an unliganded neurophysin and its vasopressin complex: Implications for binding and allosteric mechanisms. Protein Sci 10: 1869-1880. doi:10.1110/ps.10601

Yang W, Willemse J, Sawyer EB, Lou F, Gong W, Zhang H, Gras SL, Claessen D, Perrett S. 2017. The propensity of the bacterial rodlin protein RdlB to form amyloid fibrils determines its function in Streptomyces coelicolor. Sci Rep 7: 42867. doi:10.1038/srep42867

Zeng G, Vad BS, Dueholm MS, Christiansen G, Nilsson M, Tolker-Nielsen T, Nielsen PH, Meyer RL, Otzen DE. 2015. Functional bacterial amyloid increases Pseudomonas biofilm hydrophobicity and stiffness. Front Microbiol 6: 1099.

Zheng Y, Joo HS, Nair V, Le KY, Otto M. 2018. Do amyloid structures formed by Staphylococcus aureus phenol-soluble modulins have a biological function? Int J Med Microbiol 308: 675-682.

Zhong C, Gurry T, Cheng AA, Downey J, Deng Z, Stultz CM, Lu TK. 2014. Strong underwater adhesives made by selfassembling multi-protein nanofibres. Nat Nanotechnol 9: 858-866. doi:10.1038/nnano.2014.199

Zhou Y, Blanco LP, Smith DR, Chapman MR. 2012. Bacterial amyloids. Methods Mol Biol 849: 303-320. doi:10.1007/ 978-1-61779-551-0_21

Zogaj X, Bokranz W, Nimtz M, Römling U. 2003. Production of cellulose and curli fimbriae by members of the family Enterobacteriaceae isolated from the human gastrointestinal tract. Infect Immun 71: 4151-4158. doi:10 $.1128 /$ IAI.71.7.4151-4158.2003 


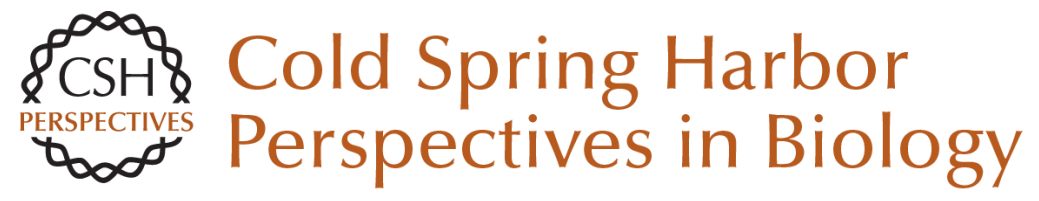

\section{Functional Amyloids}

Daniel Otzen and Roland Riek

Cold Spring Harb Perspect Biol 2019; doi: 10.1101/cshperspect.a033860 originally published online May 14, 2019

\section{Subject Collection Protein Homeostasis}

Proteome-Scale Mapping of Perturbed

Proteostasis in Living Cells

Isabel Lam, Erinc Hallacli and Vikram Khurana

Pharmacologic Approaches for Adapting Proteostasis in the Secretory Pathway to

Ameliorate Protein Conformational Diseases Jeffery W. Kelly

Cell-Nonautonomous Regulation of Proteostasis in Aging and Disease

Richard I. Morimoto

The Autophagy Lysosomal Pathway and

Neurodegeneration

Steven Finkbeiner

Functional Modules of the Proteostasis Network Gopal G. Jayaraj, Mark S. Hipp and F. Ulrich Hartl

Protein Solubility Predictions Using the CamSol Method in the Study of Protein Homeostasis Pietro Sormanni and Michele Vendruscolo

Recognition and Degradation of Mislocalized

Proteins in Health and Disease

Ramanujan S. Hegde and Eszter Zavodszky

The Nuclear and DNA-Associated Molecular Chaperone Network

Zlata Gvozdenov, Janhavi Kolhe and Brian C. Freeman
The Amyloid Phenomenon and Its Significance in Biology and Medicine

Christopher M. Dobson, Tuomas P.J. Knowles and Michele Vendruscolo

A Chemical Biology Approach to the Chaperome

in Cancer--HSP9O and Beyond

Tony Taldone, Tai Wang, Anna Rodina, et al.

Proteostasis in Viral Infection: Unfolding the Complex Virus-Chaperone Interplay Ranen Aviner and Judith Frydman

The Proteasome and Its Network: Engineering for Adaptability Daniel Finley and Miguel A. Prado

Functional Amyloids Daniel Otzen and Roland Riek

Chaperone Interactions at the Ribosome Elke Deuerling, Martin Gamerdinger and Stefan G. Kreft

Mechanisms of Small Heat Shock Proteins Maria K. Janowska, Hannah E.R. Baughman, Christopher N. Woods, et al.

Structure, Function, and Regulation of the Hsp90 Machinery

Maximilian M. Biebl and Johannes Buchner

For additional articles in this collection, see http://cshperspectives.cshlp.org/cgi/collection/

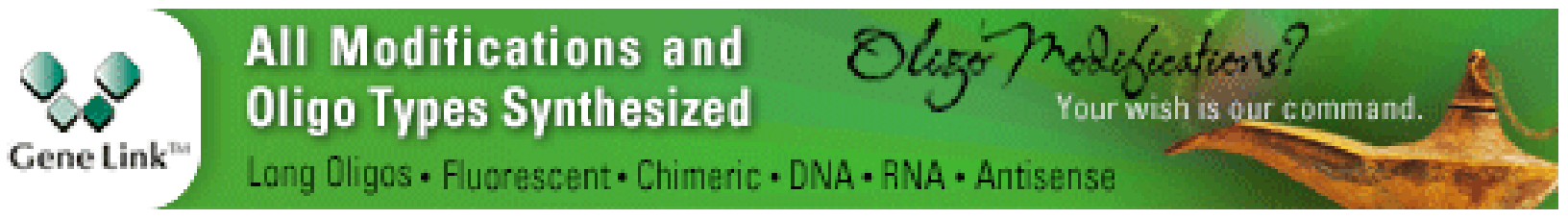


For additional articles in this collection, see http://cshperspectives.cshlp.org/cgi/collection/

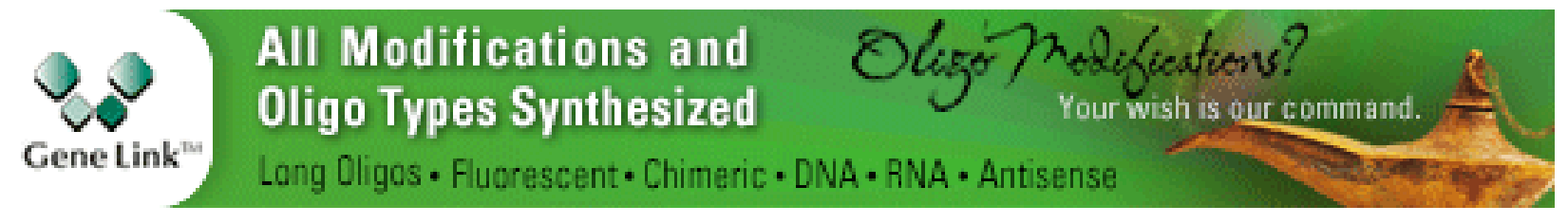

Copyright @ 2019 Cold Spring Harbor Laboratory Press; all rights reserved 